Universidade de Brasília - UnB

Curso de Pós-Graduação em Gestão Hoteleira Sustentável

\title{
PLANO PARA IMPLANTAÇÃO DE \\ UMA POUSADA ECOLÓGICA NA CHAPADA IMPERIAL
}

JACIRA MARIA ANDRADE SILVA

Brasília-DF 


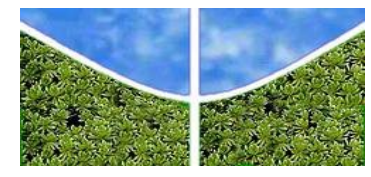

Universidade de Brasília - UNB

Centro de Excelência em Turismo - CET

Pós-graduação Lato Sensu

Curso de Especialização em Gestão Hoteleira Sustentável

\author{
PLANO PARA IMPLANTAÇÃO DE \\ UMA POUSADA ECOLÓGICA NA CHAPADA IMPERIAL
}

JACIRA MARIA ANDRADE SILVA

Projeto apresentado ao Curso de Pós-Graduação em Gestão Hoteleira Sustentável da Universidade de Brasília - UnB, como requisito parcial à sua aprovação e obtenção do título de Especialista, sob a orientação do Professor Doutor Gilson Zehetmeyer Borda.

Brasília-DF 
Universidade de Brasília - UNB

Centro de Excelência em Turismo - CET

Pós-graduação Lato Sensu

Curso de Especialização em Gestão Hoteleira Sustentável

\section{PLANO PARA IMPLANTAÇÃO DE \\ UMA POUSADA ECOLÓGICA NA CHAPADA IMPERIAL}

JACIRA MARIA ANDRADE SILVA

BANCA EXAMINADORA

Orientador: Professor Doutor Gilson Zehetmeyer Borda

Professora Doutora lara Lúcia Gomes Brasileiro

Professora Doutora Márcia Elizabeth Bortone 


\section{SUMÁRIO}

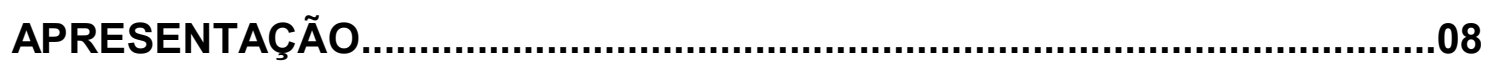

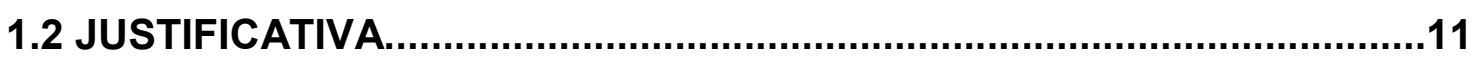

1.3 Identificação do problema de pesquisa......................................................11

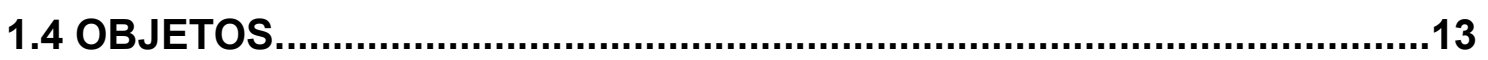

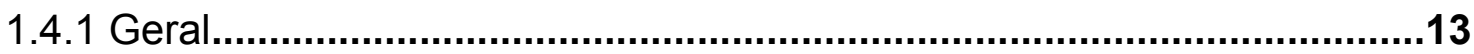

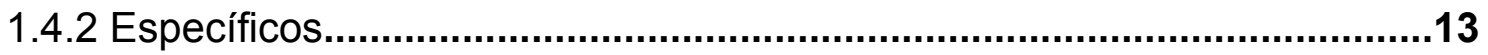

1.5 Importância do Projeto..........................................................................13

1.6 Fatores de Localização............................................................................14

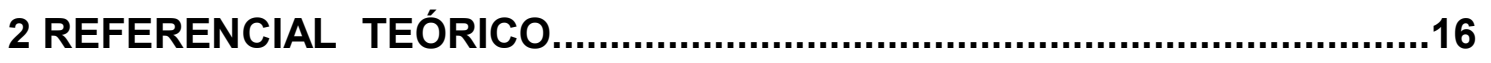

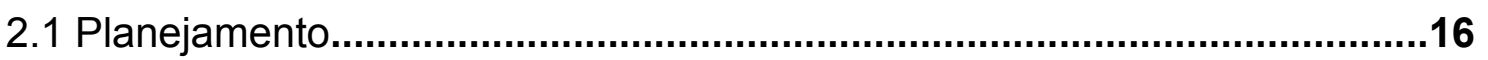

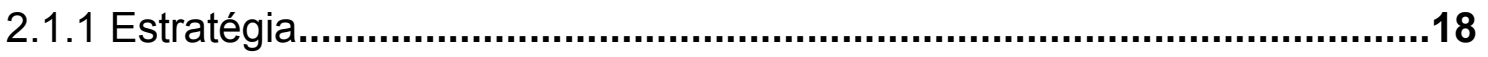

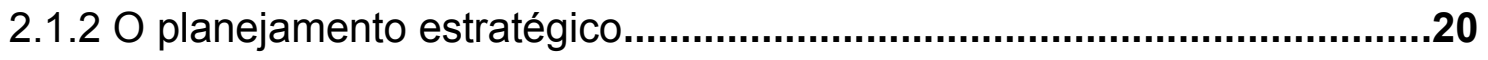

2.2 Desenvolvimento Sustentável.................................................................23

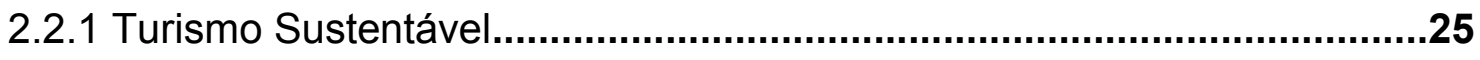

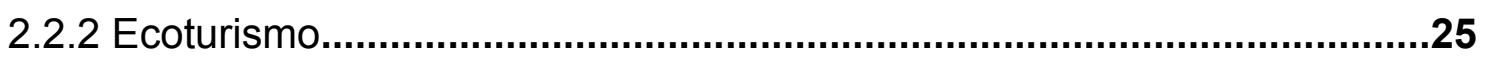

2.2.3 Desenvolvimento Sustentável e a Hotelaria..........................................28

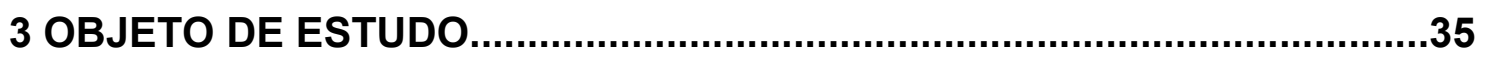

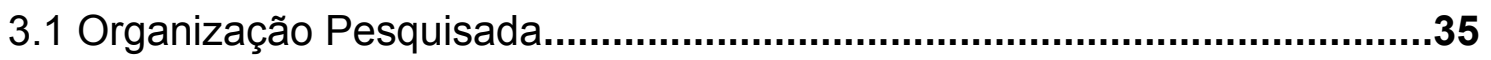

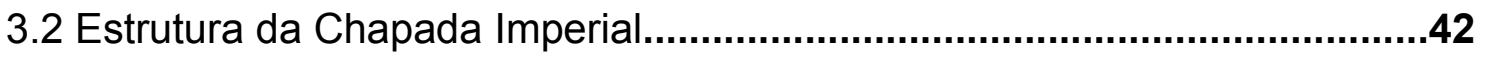

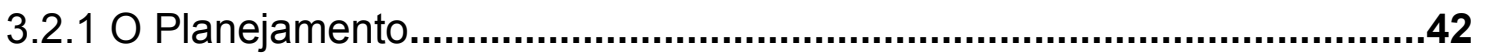

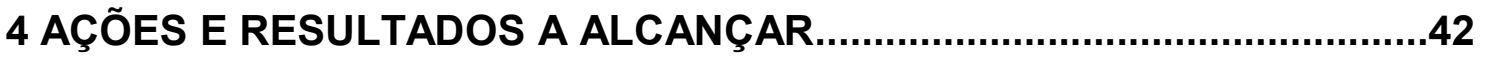

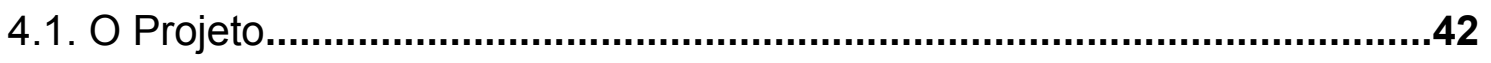

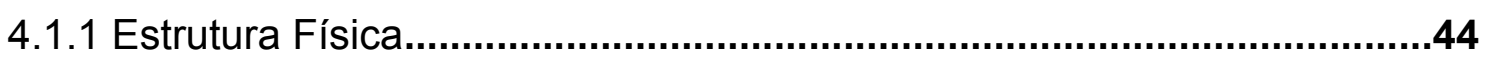

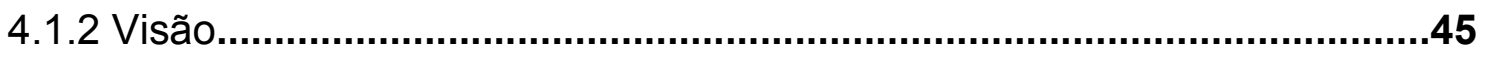

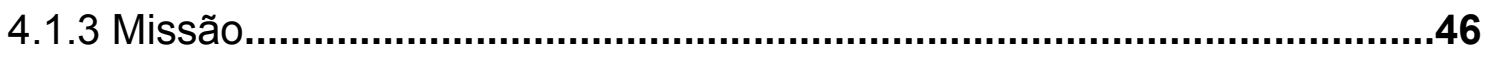

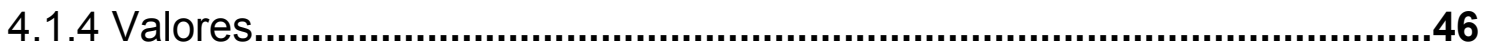

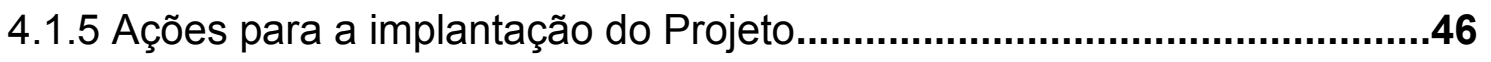

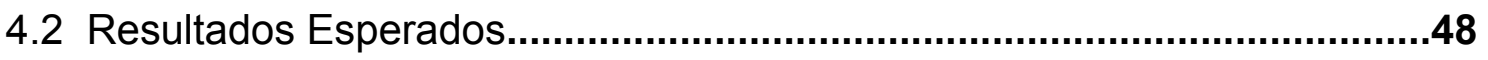

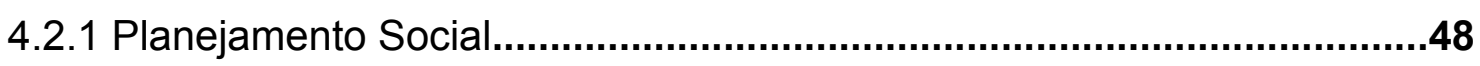

4.2.2 Planejamento Ambiental......................................................................49

4.2.3 Planejamento Econômico financeiro..........................................................47

5 CRONOGRAMA DE EXECUÇÃO DO PROJETO......................................57 
6 METODOLOGIA...................................................................................58

CONSIDERAÇÕES FINAIS.....................................................................63

REFERÊNCIAS BIBLIOGRÁFICAS ......................................................65

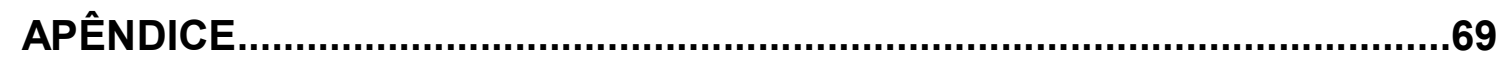

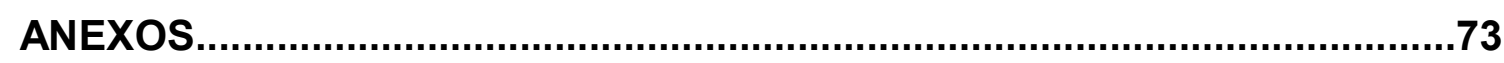




\section{LISTA DE FIGURAS}

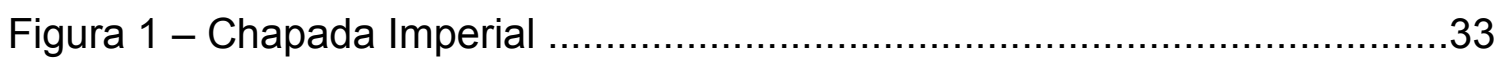

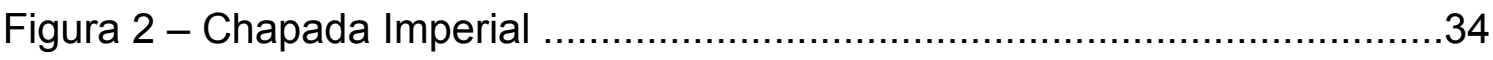

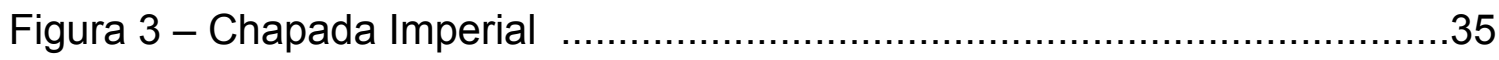

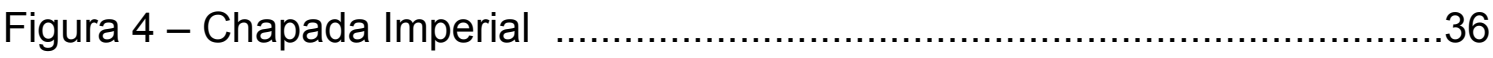

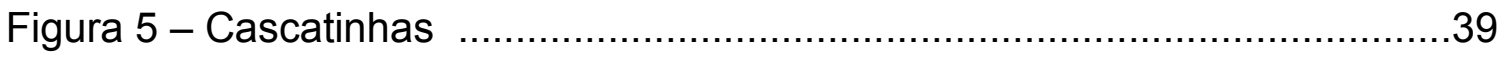

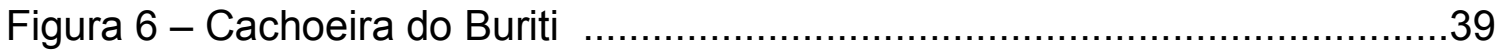

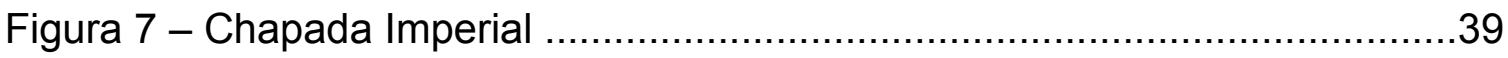




\section{LISTA DE TABELAS E GRÁFICOS}

Tabela 1 - Construção de Chalé ................................................................43

Tabela 2 - Proposta Inicial de Móveis e Equipamentos ..................................48

Tabela 3 - Orçamento de Investimentos Programados …................................49

Tabela 4 - Projeções de Depreciação Anual .................................................50

Tabela 5 - Orçamento de Custos Variáveis Anuais …………..........................51

Tabela 6 - Projeção de Faturamento Anual com Diária da Pousada Ecológica

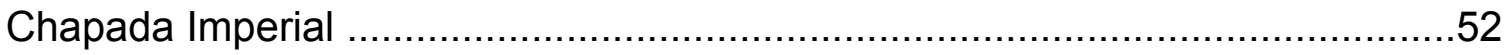

Tabela 7 - Avaliação da Viabilidade Financeira - Pousada Ecológica Chapada

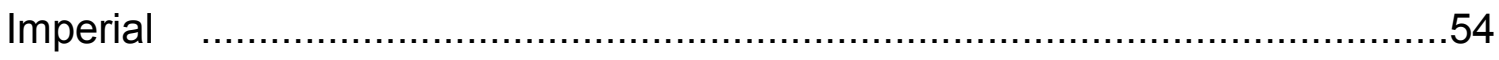

Tabela 8 - Cash Flow - Pousada Ecológica Chapada Imperial - 05 anos............55

Tabela 9 - Previsão de Destino do Fluxo de Caixa - 05 anos ..............................55

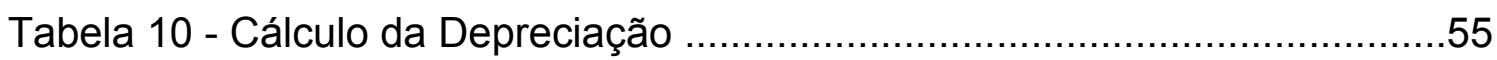

Gráfico Cash Flow - Pousada Ecológica Chapada Imperial - 05 anos.................56 


\section{RESUMO}

É importante que se perceba a problemática da falta de locais adequados e de empreendimentos hoteleiros que se encaixem nos padrões sustentáveis de consumo e que adotem estratégias consolidadoras do ecoturismo como alternativa de sustentabilidade local. Nesse sentido, o objetivo desse projeto é demonstrar aos investidores a viabilidade econômica financeira de uma pousada que será construída com técnicas ecológicas, demonstrando, mais especificamente, a viabilidade da implantação de uma Pousada Ecológica na Chapada Imperial, em Brazlândia-DF. A pesquisa é qualitativa, pois considera que há uma relação dinâmica entre o mundo real e o sujeito. A interpretação dos fenômenos e a atribuição de significados são básicas no processo de pesquisa qualitativa. Com conclusão se entende que a proposta formulada pela acadêmica mostrou-se viável para o propósito a que se destinou, embora necessite de melhorias no que concerne à definição de critérios para a análise de significância dos impactos ambientais e a metodologia de pontuação a ser adotada.

Palavras-chave: Padrões Sustentáveis, Viabilidade Econômico-Financeira, Pousada Ecológica, Chapada Imperial, Viável. 


\section{APRESENTAÇÃO}

$\mathrm{Na}$ busca por alternativas de desenvolvimento sustentável, o turismo, precisamente o naturalista, em sua modalidade turismo ecológico ou ecoturismo, apresenta-se como uma opção de atividade econômica, pautada nas potencialidades naturais de diversas regiões do Brasil.

A despeito das perspectivas, a exploração dos recursos naturais tem suscitado a preocupação dos países desenvolvidos em relação à manutenção desses recursos.

Segundo dados da Organização Mundial de Turismo (OMT), no ano de 2025 cerca de $83 \%$ da população mundial, prevista para 8,5 bilhões de habitantes, estarão vivendo nos países em desenvolvimento, para os quais o poder público deverá estimular alternativas de auto-sustentação econômica, pautada na preservação ambiental.

Nesse contexto, como resposta a essas discussões, surge o Ecoturismo, inicialmente na forma de turismo de natureza, o que na verdade já existia e vinha sendo desenvolvido há algum tempo, denominado de turismo ecológico. O Ecoturismo apresenta outra concepção, por meio do uso do patrimônio natural, sem comprometimento para as futuras gerações, assim como a promoção do bem-estar das comunidades envolvidas, baseado em um conceito, no qual se identifica a questão da consciência ambientalista.

Vale destacar que o projeto Pousada Ecológica Chapada Imperial se desenvolverá a partir das bases conceituais do ecodesenvolvimento, sintetizado na seguinte expressão: o ecodesenvolvimento é um projeto de Estados e Sociedades, cujo centro de desenvolvimento econômico é a Sustentabilidade Social e Humana, capaz de ser solidária com a biosfera (PEREIRA, 2001).

O Turismo Ecológico é uma atividade com grande potencial de expansão no país. A exploração do setor no Brasil, em comparação a outros países, é baixa, apesar do patrimônio natural aqui existente. Uma das regiões do país, com destaque 
turístico do Ecológico, são os Estados de Goiás, Mato Grosso na Amazônia, no qual o número de empreendimentos dobrou, nos últimos quatro anos.

No Distrito Federal, apesar de já existirem vários empreendimentos hoteleiros que exploram este segmento, o turismo ecológico vem sendo, ainda que muito devagar, trabalho pelas entidades governamentais ligadas ao turismo. Graças aos atrativos naturais e demanda, identificou-se a oportunidade de abertura de uma Pousada Ecológica na Chapada Imperial que será constituída obedecendo aos padrões da sustentabilidade ambiental, social e econômica.

A Chapada Imperial fica há menos de $50 \mathrm{~km}$ do centro de Brasília, no ponto mais alto do Distrito Federal (1.347 m) na Fazenda Dois Irmãos, na Rodovia DF-220, Km 9, no município de Brazlândia.

Dessa forma, o objetivo geral deste estudo é propor a implantação de uma pousada Implantação de um projeto de Pousada Ecológica na Chapada Imperial.

Para realização do estudo, foram utilizados os métodos de coleta por observação, mediante pesquisas realizadas em pousadas na Chapada Imperial, entrevistas estruturadas, pesquisa de mercado e estudo bibliográfico.

A pesquisa mostrou que a Chapada Imperial apresentou uma demanda considerável, para obter taxa de ocupação alta no futuro empreendimento. $\mathrm{Na}$ análise de viabilidade financeira, procurou-se, em todos os levantamentos de dados, uma máxima aproximação com a realidade. Obteve-se um payback simples e uma taxa interna de retorno, ao final do $5^{\circ}$ ano, de $21 \%$.

Pelos resultados financeiros, que o investimento é viável, por isso, a pousada é um empreendimento interessante, se o empresário não necessitar do retorno do capital investido no curto ou médio prazo. 


\subsection{Justificativa}

Embora a importância Turismo Ecológico para as economias municipais esteja sempre na pauta das discussões, ainda não há um modelo de gestão hoteleira no ramo de hospedagem ecológica organizado pelo Instituto Brasileiro de Turismo - EMBRATUR. Essa falta de norteamento estimula a experimentação e os descuidos quanto ao ambiente natural, dificultando o benchmarketing de empreendimentos hoteleiros e reduzindo as vantagens competitivas.

Entende-se que o resultado do Projeto Pousada Ecológica Chapada Imperial pode dar uma contribuição para o setor hoteleiro no segmento de hospedagem ecológica à medida que a implantação de empreendimentos e de ações de melhoria sócio-ambientais e culturais sejam adequadas ao ecoturismo, atendendo dessa forma, aos preceitos do desenvolvimento sustentável.

Uma Pousada Ecológica torna-se, portanto um produto e um serviço diferenciado diante do cenário mundial de mobilização para a proteção do meio ambiente e se integra perfeitamente à prática do Ecoturismo, que é a prática do turismo responsável.

A implantação de uma Pousada Ecológica na Chapada Imperial ficará viável a consolidação do ecoturismo no Distrito Federal.

\subsection{Identificação do problema de pesquisa}

É importante que se perceba a problemática da falta de locais adequados e de empreendimentos hoteleiros que se encaixem nos padrões sustentáveis de consumo e que adotem estratégias consolidadoras do ecoturismo como alternativa de sustentabilidade local. Nesse sentido, o objetivo desse trabalho é demonstrar aos investidores a viabilidade econômica financeira de uma pousada construída com técnicas ecológicas, demonstrando, mais especificamente, a viabilidade da implantação de uma Pousada Ecológica na Chapada Imperial em Brazlândia-DF.

Neste prisma, há duas perguntas-problemas a serem respondidas são: 
- A implantação de um projeto de uma pousada ecológica na Chapada Imperial é fator relevante para o desenvolvimento sustentável?

- É viável a implantação de uma Pousada Ecológica na Chapada Imperial baseado no tripé da Sustentabilidade? 


\subsection{OBJETIVOS}

\subsubsection{Geral}

A proposta do projeto é a Implantação de um projeto de Pousada Ecológica na Chapada Imperial.

\subsubsection{Específicos}

São determinados como premissas para a consecução do Projeto em tela os seguintes Objetivos Específicos:

a) Traçar um Plano de uma Pousada;

b) Fazer o levantamento de dados ambientais, sociais e financeiros para verificar a viabilidade da implantação de uma Pousada Ecológica;

c) Propor a implantação de uma pousada Ecológica.

\subsection{Importância do Projeto}

O segmento de hospedagem ecológica vem passado por transformações rápidas, provocadas pelas exigências dos clientes e aos novos métodos de sustentabilidade social, ambiental e econômica. Assim, as atividades do Ecoturismo, desempenhadas nos empreendimentos ecológicos, têm-se dinamizado no sentido de proporcionar qualidade nos serviços prestados aos hóspedes, em função da necessidade de preservação do meio ambiente, cada vez mais presente no dia-a-dia da sociedade.

Com essas necessidades cada vez mais presente no dia-a-dia da sociedade torna importante à implantação de uma pousada ecológica, localizada na Chapada Imperial em Brazlândia-DF, viabilizado por meio de um projeto econômico financeiro, considerado ferramenta fundamental para o sucesso do empreendimento. 


\subsection{Fatores de localização}

A escolha de um local para empreendimento hoteleiro, em determinada cidade, depende de fatores que variam em relação ao tipo específico de hotel que se pretende instalar.

A escolha da melhor localização vai depender do tipo de hotel em estudo. No caso deste trabalho o foco será um hotel-pousada ecológico, que é um tipo de hotel cujas atrações giram em torno de florestas ou parques ecológicos, no interior das quais se situam.

Como exemplo e ponto de partida, aplicando-se no que couber a esta pesquisa, estão os atuais hotéis-pousada que respeitam seriamente o meio ecológico em que se inserem. Na Amazônia, pode ser mencionado o "Hotel Ariaú Amazon Towers" - o hotel na copa das árvores, com 250 apartamentos, construído sobre palafitas ao nível das copas das árvores (técnica muito utilizada pelos nativos, tem sua arquitetura regional única na região). Em seu complexo hoteleiro possui 08 torres incrustadas sobre a Selva Amazônica com localização estratégica (ARIAU, 2008).

O hotel-pousada ecológico deverá obedecer aos seguintes fatores de localização(ANDRADE, 2002):

- Localização em meio à floresta ou parque ecológico, com grande apelo turístico e paisagístico.

- Facilidade de acesso por meio de rodovia ou hidrovia.

- Terreno com grandes dimensões, que permita pratica de esporte ao ar livre, ancoradouros de barcos, parque aquático.

- Localização em terreno não inundável e relativamente protegido contra insetos.

Os hotéis podem ser classificados conforme (ANDRADE, 2002):

- O grau de conforto, a qualidade dos serviços e os preços, segundo 
classificação da Empresa Brasileira de Turismo - Embratur e da Associação Brasileira da Indústria de Hotéis - ABIH. Esse tipo de classificação, para os consumidores, tem função informativa; orientar investidores e empresários; constituir instrumento de política de incentivo às atividades turísticas, e outras.

- Sua localização: hotéis de cidade, de praia, de montanha, de aeroporto, e outros.

- Sua destinação: hotéis de turismo, negócios, lazer, cassino. 


\section{REFERENCIAL TEÓRICO}

\subsection{Planejamento}

O planejamento estratégico atual é resultado de evoluções na gestão das organizações, que alteraram, entre outros, o ambiente e a competitividade.

Segundo Rebouças (2004), "Existe certa dificuldade, quando da conceituação da função do planejamento nas empresas, de estabelecer sua real amplitude e abrangência".

Para tanto, Steiner (1969), estabelece as cinco dimensões do planejamento, cujos aspectos básicos são apresentados a seguir:

- A primeira dimensão do planejamento corresponde ao assunto abordado, que pode ser produção, pesquisa, novos produtos, finanças, marketing, instalações, recursos humanos, outros.

- A segunda dimensão corresponde aos elementos do planejamento, entre os quais podem ser citados propósitos, objetivos, estratégias, políticas, programas, orçamentos, normas e procedimentos, entre outros.

- Uma terceira dimensão corresponde à dimensão do tempo do planejamento, que pode ser, por exemplo, de longo, médio ou curto prazo.

- A quarta dimensão refere-se às unidades organizacionais onde o julgamento é elaborado, e, nesse caso, pode-se ter planejamento corporativo, de subsidiárias, de grupos funcionais, de divisões, de departamentos, de produtos etc.

- A quinta dimensão corresponde às características do planejamento que podem ser representadas por complexidade ou simplicidade, qualidade ou quantidade; planejamento estratégico ou tático, confidencial ou público, formal ou informal, econômico ou caro. 
Como conseqüência, o planejamento pode ser conceituado como um processo, considerando os aspectos abordados pelas dimensões anteriormente apresentadas, desenvolvido para o alcance de uma situação desejada de um modo mais eficiente, eficaz e efetivo, com a melhor concentração de esforços e recursos pela empresa (REBOUÇAS, 2004).

O planejamento estratégico corresponde ao estabelecimento de um conjunto de providencias a serem tomadas pelo executivo para a situação em que o futuro tende a ser diferente do passado; entretanto, a empresa tem condições e meios de agir sobre as variáveis e fatores de modo que possa exercer alguma influencia; o planejamento é, ainda, um processo contínuo, um exercício mental que é executado pela empresa independentemente de vontade especifica de seus executivos (REBOUÇAS, 2004).

No processo de tomada de decisões na empresa deve conter ao mesmo tempo os componentes individuais e organizacionais, bem como a ação nesses dois níveis deve ser orientada de tal maneira que garanta certa confluência de interesses dos diversos fatores alocados no ambiente da empresa.

Toda a atividade de planejamento nas empresas, por sua natureza, deverá resultar de decisões presentes, tomadas a partir do impacto das mesmas no futuro, o que the proporciona uma dimensão temporal de alto significado (REBOUÇAS, 2004).

A finalidade do projeto pode ser definida como o desenvolvimento de processos, técnicas e atitudes administrativas, as quais proporcionam uma situação viável de avaliar as implicações futuras de decisões presentes em função dos objetivos empresariais que ajudarão a tomada de decisão no futuro, de maneira mais rápida, coerente, eficiente e eficaz. Dentro deste raciocínio, pode-se afirmar que o exercício sistemático do planejamento tende a reduzir a incerteza envolvida no processo decisório e, por conseqüência, provocar o aumento da probabilidade de alcance dos objetivos, desafios e metas estabelecidos para a empresa.

Um processo contínuo, composto de várias etapas, funciona de forma não linear em decorrência de haver variabilidade nas empresas. Essa variabilidade é devida às pressões ambientais que a empresa tem de suportar e são resultantes de 
forças externas, continuamente em alteração com diferentes níveis de intensidade de influência, bem como das pressões internas, resultantes dos vários fatores que integram a empresa.

Com nenhuma preocupação de estabelecer todas as características básicas da função planejamento como um processo contínuo, apresenta-se a seguir, alguns dos principais aspectos:

a) O planejamento não diz respeito a futuras decisões, mas às implicações de decisões presentes (DRUCKER, 1962, p. 131 apud REBOUÇAS, 2004). Portanto, aparece como um processo sistemático e constante de tomada de decisões, cujos efeitos e conseqüências deverão ocorrer em futuros períodos de tempo.

b) O planejamento não é um ato isolado. Portanto deve ser visualizado como um processo composto de ações inter-relacionadas e interdependentes que visam ao alcance de objetivos previamente estabelecidos.

c) O processo de planejamento é muito mais importante que seu resultado final. O resultado final do processo de planejamento, normalmente, é o plano, sendo que este deve ser desenvolvido "pela" empresa e não "para" a empresa. Sendo desrespeitado esse aspecto, têm-se planos inadequados para a empresa, tal como uma resistência e descrédito efetivos para sua implantação.

Os sistemas de avaliação e as medidas de performance tradicionais muitas vezes não são capazes de fornecer as informações necessárias para a direção de uma empresa.

\subsubsection{Estratégia}

Nesse sentido, relativamente aos conceitos de estratégia, Bethlem (1998) diria que o conceito de estratégia e as ações relativas a ele - isto é, planejamento, elaboração, execução, implantação, acompanhamento, controle, avaliação etc. - 
"têm que ser ensinados aos atores e serem não só aprendidos, como também adotados por eles como válidos e úteis".

Mintzberg (1999) considera que a estratégia, atualmente, é uma ferramenta gerencial imprescindível para as empresas. De acordo com Thompson Jr. e Strickland III (2000), a estratégia da empresa é um

Conjunto de mudanças competitivas e abordagens comerciais que os gerentes executam para atingirem o melhor desempenho da empresa, buscando reforçar a posição da organização no mercado, promover a satisfação dos clientes e atingir os objetivos de desempenho.

Para Ansoff (1990), estratégia é, basicamente, a utilização dos diversos recursos empresariais, como humanos, técnicos e financeiros, que estão à disposição do empresário. Ao adotar uma estratégia, o empresário deve analisar sua organização e o contexto em que está inserido, estabelecendo caminhos, cursos e programas de ação que devem ser seguidos para o alcance dos objetivos definidos pela empresa.

As empresas que sobrevivem e têm sucesso são organizações aprendizes (learning organizations), o que chega a ser considerado como novidade.

Segundo Bethlem (1998), na área Estratégica são enormes as dificuldades semânticas, chegando a dizer que na aprendizagem há uma "debilidade dos conceitos básicos", impossibilitando o sucesso. Assim, deixa de lado a questão, para citar alguns fatos que para ele chegam a ser "claros e bem definidos" (BETHLEM, 1998):

1. Estratégia é um conceito que precisa ser aprendido (aprender significa saber utilizar, pois, sem saber utilizar um conceito não há como aplicálo);

2. Estratégia para ser tornada real, ou seja, bem executada, tem que ser aprendida por várias pessoas e aceita por todas elas;

- A transformação de idéias "estratégicas" em ações "estratégicas" que venham dar aos estrategistas os resultados que almejam. 
Conforme Bethlem (1998), em determinada organização as ações estratégicas poderiam ser encetadas sem que tenham sido elaborados planos ou obtida a cooptação, ocorrendo o que alguns, entre eles, chamam de estratégia emergente. Os agentes agiriam improvisando em função das circunstâncias.

Segundo Mintzberg (1979), trata-se de um fenômeno parecido com o da personagem Mr. Jourdan (de Molière), que sempre falou em prosa e não sabia. As estratégias emergentes, para funcionarem, necessitam, como qualquer ação humana, de cooptação. Mesmo que ocorra o que se chama de obediência cega, alguém mandou e alguém concordou em obedecer; mandantes e obedientes têm que pôr mãos à obra em concordância e, como diz Barnard (1964), de maneira coordenada e cooperativa, para que as idéias se concretizem em ações do mundo real. Portanto, não se manda naquilo que não se sabe e não se executa o que não se sabe. A aprendizagem está presente em toda ação inteligente.

\subsubsection{O planejamento estratégico}

As organizações vêm utilizando amplamente o planejamento estratégico como uma ferramenta da gestão empresarial. Oliveira considera o planejamento estratégico como "um instrumento administrativo relacionado à estratégia empresarial, pois é a sustentação do desenvolvimento e da implementação de estratégias empresariais" (OLIVEIRA, 1991).

Em relação ao passado, segundo Kaplan (1999), existem dois problemas fundamentais em relação à forma usada no passado pelas empresas para medir a sua performance:

- Os sistemas financeiros tradicionais não conseguem identificar com precisão os fatores internos, como produtos, mercados ou clienteschave, que impulsionam os lucros e custos de uma empresa;

- Os resultados financeiros atuais raramente permitem prever a performance no futuro. Isoladamente, os indicadores financeiros não revelam, por exemplo, se a direção está ou não criando valor futuro para a empresa, por meio do desenvolvimento de novos produtos e o aumento da qualidade e da satisfação dos clientes. 
Para os problemas acima Kaplan (1999) sugere dois métodos que os abordam: o balanced scorecard - quadro equilibrado de indicadores - e a ABM (activity based management) - gestão baseada em atividades.

Durante muitos anos as medidas contábil-financeiras eram os principais meios para a obtenção de informações sobre o desempenho da empresa, sendo que, em sua maioria, essas medidas foram desenvolvidas para uma economia industrial, o que dependia, principalmente, da eficácia dos executivos em investir e administrar recursos físicos e tangíveis.

Hoje, essas medidas contábil-financeiras já não são mais suficientes, uma vez que a revolução industrial trouxe grandes desafios que implicam na existência de quatro eras de qualidade:

a) da Inspeção

b) do Controle Estatístico de Qualidade

c) da Garantia de Qualidade

d) da Gestão Estratégica de Qualidade.

$\mathrm{Na}$ era da inspeção quem inspecionava o produto acabado era o funcionário e havia incertezas quanto aos produtos. Na era do controle estatístico de qualidade a preocupação com o processo se fez presente, controlando estatisticamente, verificando os produtos, as peças que saíam das máquinas.

A era de garantia de qualidade foi marcada pela padronização, mas sua forma final dependia do funcionário com que ele estivesse envolvido.

A era da gestão estratégica de negócio foi marcada pela necessidade de rapidez, de mais qualidade, do uso da tecnologia e da informação. Com isso, era necessário que as empresas mudassem suas estruturas, que se tornassem mais "enxutas" e que fossem aproveitadas as oportunidades, tendo como suporte sistemas de informação integrados e, quando se trata de estratégia a organização como um todo deve estar focada em seus objetivos. Com isso, as organizações que puderem direcionar suas ações pautadas em suas estratégias, vislumbrando o futuro, estarão praticando a administração estratégica. 
A administração estratégica, portanto, é a forma como a organização formula, traduz, comunica, implementa e controla a estratégia previamente definida. A evolução do processo de administração estratégica está relacionada ao ritmo acelerado das transformações que ocorrem. Vale ressaltar que até a década de 50 , o ritmo dessas transformações, tanto na sociedade em geral quanto no mundo dos negócios, era relativamente lento e uniforme. A partir desse período, os critérios da administração científica e do profissionalismo nos negócios superaram a visão empírica e romântica da gestão. No curso dessa evolução inaugura-se um novo paradigma: a era da gestão estratégica e competitiva.

Assim, a estratégia de uma organização descreve como ela pretende criar valor para seus acionistas, clientes e cidadãos. Se os ativos intangíveis da organização representam mais de $75 \%$ de seu valor, a formulação e a execução da estratégia deve tratar explicitamente da mobilização e alinhamento dos ativos intangíveis (KAPLAN, 1999).

No ritmo das mudanças cada vez mais aceleradas, os anos 90 testemunharam o processo de valorização da gestão estratégica, dando um enfoque mais sistêmico ao processo de planejamento. Assim, para a escola de gestão estratégica, além de planejar estrategicamente, é preciso organizar, dirigir, coordenar e coordenar de modo estratégico.

Com isso, a implementação da gestão estratégica proporcionou uma visão mais integrada e menos centralizada das funções administrativas. Conseqüentemente, o conceito tradicional de pensamento estratégico centralizado tornou-se inadequado na medida em que, para os gerentes, bastava planejar, coordenar e controlar. E, essas ações não só focalizavam, preferencialmente, as atividades internas da organização como privilegiavam, também, uma atitude reativa para fazer frente às mudanças que aconteciam no ambiente externo e no ambiente interno.

A gestão estratégica procurou enfocar, sistematicamente, as funções estratégicas para estabelecer o equilíbrio entre as demandas dos ambientes interno e externo, buscando, ainda, integrar todos os setores da organização, de forma a alocar recursos de maneira a melhor atingir seus objetivos e suas metas. 


\subsection{Desenvolvimento Sustentável}

Segundo Ruschmann (2006) o desenvolvimento turístico geralmente é enfocado do ponto de vista econômico, que utiliza uma abordagem baseada nos mecanismo dos preços, numa visão comercial. Porém, os aspectos sociais, culturais e ambientais da atividade não podem ser negligenciados e exigem envolvimento direto e estudo, por parte das entidades governamentais.

O turismo contemporâneo tem buscado ressaltar o aspecto natural, o que pode ser devido à busca do verde e à fuga dos tumultos dos grandes conglomerados urbanos, pelas pessoas que tentam recuperar o equilíbrio psicofísico, em contato com ambientes naturais, durante o seu tempo de lazer. De acordo com Faria (2001), a origem do conceito de sustentabilidade remete as relações entre os seres humanos e o meio ambiente (recursos naturais). Dessa maneira, fornece alguns conceitos:

a) Uso sustentável - ocorre quando os seres humanos utilizam os recursos renováveis, permitindo a reposição dos processos naturais e, consequentemente, a renovação indefinidamente, do sistema;

b) Crescimento sustentável - é uma questão fundamental se o crescimento econômico considera ou não a limitação de recursos, sem o que ocorrerá degradação do ambiente, pois não haverá crescimento sustentável sem o controle do crescimento populacional e do consumo per capta de recursos.

Nesse sentido, Matheus, Moraes e Caffagni (2005) entendem que

O conceito de desenvolvimento sustentável, embora polêmico, foi um grande avanço e representa uma tentativa de conseguir o bem-estar aliado à segurança de condições de vida satisfatórias no futuro (Bursztyn, 1994). Os caminhos que o homem percorre na busca por progresso, crescimento e desenvolvimento levam a impasses atuais relevantes, requerendo a escolha de estratégias adequadas que levem em consideração a preservação da qualidade ambiental. O objetivo fundamental seria a promoção de um desenvolvimento sócio-econômico eqüitativo e com qualidade ambiental.

A Conferência das Nações Unidas sobre o Meio Ambiente e Desenvolvimento (1998) aponta três princípios para o alcance das metas para o desenvolvimento sustentável, que são: 
1. Equidade social: significa a disposição para reconhecer igualitariamente o direito de cada um;

2. Eficiência econômica: distribuição e a gestão dos recursos econômicos e financeiros feita de forma planejada, para garantir o funcionamento eficiente do sistema;

3. Prudência ecológica: adoção de ações que visam aos seguintes pontos:

a) Reduzir o consumo de recursos naturais e a produção de resíduos (lixo);

b) Intensificar as pesquisas e a introdução de tecnologias limpas;

c) Definir regras que permitam uma adequada proteção ambiental.

Inspirado na Conferência de Estocolmo, em 1972, foi criado um relatório que propôs os três pilares da sustentabilidade (NELSON; PEREIRA, 2004), que são:

- Sustentabilidade ambiental ou ecológica: é uma das áreas mais reconhecidas pelo público por causar danos visíveis, muitas vezes pelo turismo. A indústria deve repensar onde construir, que materiais usar $\mathrm{e}$ que atividades oferecer ao visitante, além de optar pelo uso de materiais mais benéficos ao meio ambiente, como detergentes biodegradáveis e energia alternativa, a fim de evitar poluição e sobrecarga do ambiente;

- Sustentabilidade sociocultural: é importante que a comunidade seja envolvida no planejamento das atividades, evitando atritos e degradações, pois "quando se escuta a voz da comunidade e essa faz parte do planejamento da atividade, ocorre que o nível de impacto é menor e a atividade melhor sucedida" (NELSON; PEREIRA, 2004);

- Sustentabilidade econômica: a indústria turística deve empenhar-se em atuações eqüitativas, que evitam a perda de dinheiro e reconhecer que impactos ambientais, sociais e culturais também podem ter 
repercussões em nível econômico.

Deve-se tentar equilibrar esses três pilares de forma a se manter uma gestão eficaz da empresa. Com base no atual conceito de sustentabilidade empresarial, as três dimensões possuem o mesmo grau de importância e cada qual contribui e interage para o fortalecimento das outras duas dimensões.

\title{
2.2.1 Turismo Sustentável
}

O conceito de turismo sustentável está ligado à sustentabilidade do meio natural e cultural, considerados como atrativos básicos do turismo, não se pode, no entanto, dissociar o desenvolvimento sustentável da dimensão econômica e social.

\begin{abstract}
E inquestionável a importância para o turismo da presença de cenários naturais, como florestas, rios e lagos de águas límpidas, montanhas e serras, com ar puro, diversidade de animais, objetivando despertar a curiosidade daqueles que não convivem com essas espécies. No entanto, o crescimento vertiginoso, nos últimos anos, do setor de turismo, mesmo mostrando benefícios mensurados pela geração de empregos diretos e indiretos e crescimento econômico dos núcleos turísticos receptores, disfarça os passivos sócio-ambientalistas decorrentes desta atividade (NELSON; PEREIRA, 2004).
\end{abstract}

Dessa maneira, o conceito de sustentabilidade pode se transformar em uma questão mais política que ambiental, reflexo de conflitos e da pluralidade de atores envolvidos, muitos deles afetados, ou mesmo responsáveis, por episódios de degradação ambiental.

Segundo Pires (1999), o turismo sustentável tem como objetivo atender as necessidades de lazer dos turistas e de desenvolvimento dos núcleos receptores, preservando o meio ambiente local.

Assim, de acordo com o Tourism Concern (1999):

O turismo sustentável opera de acordo com a capacidade de suporte dos
pólos receptores, possibilitando a regeneração e reprodução dos recursos
naturais, reconhecendo e incentivando a contribuição das comunidades
locais por meio de suas manifestações culturais para o desenvolvimento
turístico. Além disso, do ponto de vista do turismo sustentável, como já foi
mencionado, deverá sempre haver uma distribuição eqüitativa dos
benefícios econômicos advindos das atividades recreacionais, enfatizando a
participação da população local na tomada de decisões.

As características do ambiente são as motivadoras do turismo ecológico, 
por isso é preciso mantê-las em equilíbrio para que o próprio negócio possa realizarse por um longo tempo, daí a importância do conceito de desenvolvimento sustentável.

Dessa forma, qualquer discussão sobre planejamento e capacitação profissional de empreendedores de turismo rural não pode restringir-se apenas a formação técnica, mas estar permeada pela consciência da sustentabilidade.

Entende-se como sustentável o desenvolvimento harmônico e integrado que gera retorno econômico, respeitando o meio ambiente natural e sociocultural.

O turismo sustentável enfrenta vários problemas, pois, com o passar do tempo, o aumento da demanda e o objetivo de melhorar cada vez mais o seu produto turístico, algumas propriedades tendem a ultrapassar o ponto de equilíbrio, aumentando demasiadamente a possibilidade de recepção ou descaracterizando o local para permitir o atendimento de um numero maior de pessoas.

Essas modificações sem planejamento descaracterizam os elementos que, muitas vezes, eram os principais atrativos do local: a simplicidade, a rusticidade, o atendimento familiar, a comida caseira, entre outros.

O número de novos empreendimentos cresce continuamente. Muitos prosperam para depois passar por um período de consolidação e amadurecimento e, após esse período, em decorrência do aumento concorrencial e do grau de exigência do consumidor, vem à seleção.

No momento da seleção os despreparados e sem planejamento apresentam grandes dificuldades operacionais, os bem estruturados, contudo, continuam a crescer de maneira menos proeminente que na fase inicial, mas que permite resultados satisfatórios.

Deve-se, portanto, buscar uma consolidação que torne a pousada uma opção de lazer e renda em longo prazo, permitindo-se que as características locais sejam preservadas e que as necessidades e expectativas do turista sejam atendidas, além de possibilitar o desenvolvimento de uma consciência sustentável, ao oferecer ao visitante a possibilidade de vivenciar uma relação diferenciada com o ambiente. 


\subsubsection{Ecoturismo}

O ecoturismo é uma atividade sustentável e que se preocupa com a preservação do patrimônio natural e cultural, diferentemente, do turismo convencional. Essa tendência varia desde a pratica do esporte radical ao estudo cientifico dos ecossistemas.

O ecoturismo visa:

a) Promover e desenvolver turismo com bases cultural e ecologicamente sustentáveis; promover e incentivar investimentos em conservação dos recursos culturais e naturais utilizados;

b) Fazer com que a conservação beneficie materialmente as comunidades envolvidas, pois somente servindo de fonte de renda alternativa, estas se tornarão aliadas de ações conservacionistas;

c) Ser operado de acordo com critérios de mínimo impacto para ser uma ferramenta de proteção e conservação ambiental e cultural;

d) Educar e motivar pessoas, por meio de participação, em atividades que possa perceber a importância de área natural e culturalmente conservada.

A Política Nacional de Ecoturismo, apresentada pela EMBRATUR (1996), estabeleceu um processo de planejamento participativo, para a elaboração de diretrizes para uma política brasileira que considera o ecoturismo como

O segmento da atividade turística que utiliza, de forma sustentável, o patrimônio natural e cultural, incentiva sua conservação e busca a formação de uma consciência ambiental, por meio da interpretação do ambiente, promovendo o bem-estar das populações envolvidas.

O ecoturismo, para que se estruture de forma sólida, acessível e permanente, deve estar alicerçado em diretrizes coerentes com o mercado, tecnologicamente ajustadas e democraticamente discutida, de forma a acomodar adequadamente as peculiaridades de cada ecossistema e de cada traço cultural. 


\subsubsection{Desenvolvimento Sustentável e a Hotelaria}

O meio ambiente chamou a atenção dos economistas no início dos anos 70, devido a grande exploração das áreas de pesca, a poluição e a degradação ambiental. Strong (1995) sugere o conceito de "ecodesenvolvimento", que é sistematizado posteriormente por Sachs (1993):

Desenvolvimento endógeno e dependendo de suas próprias forças,
submetido á lógica das necessidades do conjunto da população, consciente
de sua dimensão ecológica e buscando estabelecer uma relação de
harmonia entre o homem e a natureza.

O movimento do Ecodesenvolvimento teve início na Conferência de Estocolmo com Meadows, destacando-se, em 1992, com a Conferência Mundial para o Desenvolvimento e Meio Ambiente no Rio de Janeiro, sendo empregado pela primeira vez este conceito para definir políticas de desenvolvimento, por Strong (1995).

De acordo com Sachs (1993), há seis princípios básicos do ecodesenvolvimento:

a) a satisfação das necessidades básicas;

b) a solidariedade com as gerações futuras;

c) a participação da sociedade envolvida;

d) a preservação dos recursos naturais e do meio ambiente em geral;

e) a elaboração de um sistema social garantido emprego, segurança social e respeito a outras culturas;

f) programas de educação.

Segundo Sachs (1993), o conceito de desenvolvimento sustentável combina eficiência econômica com equidade social, na medida em que o aumento da riqueza alcançada pela melhor produtividade tenha distribuição equânime entre os povos. 
A tecnologia tem importante contribuição para o desenvolvimento sustentável, pois o ecodesenvolvimento requer tecnologias sadias e limpas. Essa questão, no entanto, é complexa devido aos interesses econômicos mundiais que dividem o mundo em países desenvolvidos e países em desenvolvimento, e às políticas públicas que nunca são efetivas devido aos interesses corporativos. Tais interesses defendem o desenvolvimento econômico e promovem a concentração populacional nos centros urbanos agravando ainda mais a carência das políticas públicas voltadas para o ecodesenvolvimento (RATTNER, 1992).

De acordo com Ferreira (1999),

Se por um lado, os grandes complexos industriais servem como atrativo de mão-de-obra, reorientando a distribuição populacional regional, por outro lado exercem forte pressão sobre o meio ambiente, na medida em que concentram as populações e incrementam as atividades poluidoras e a pressão sobre os recursos naturais, principalmente a água, colocando em risco o equilíbrio com a natureza.

Para Weber (1997), a questão do desenvolvimento em termos de gestão das interações, se processam entre as variabilidades econômicas e sociais por um lado e as variabilidades naturais por outro. Por isso, Vieira e Weber empregam o termo de "desenvolvimento viável" como a

Perspectiva das melhores modalidades possíveis de gestão das interações entre diferentes fontes (natural e social), o que difere do conceito de "desenvolvimento durável" centrado na idéia de ser a dinâmica dos recursos naturais renováveis empreendidas com base na noção de gestão de estoques.

É de comum acordo entre autores que o desenvolvimento, para ser efetivo, tem que ser sustentado. O fator essencial para se buscar o desenvolvimento sustentável é entender a função dos ecossistemas, da paisagem, e o interrelacionamento entre os organismos vivos e seu ambiente (FERREIRA, 1999).

O Primeiro Congresso Internacional do Fundo Mundial para a Vida Selvagem, chamado "A Natureza e o Homem", de 1967, em Amsterdã, aponta que o mundo natural

É essencial para o bem estar de todos os povos e constitui parte de seu patrimônio, merecendo o seu respeito... Que por estas razões, todas as pessoas, de cada geração, em todo o mundo, têm a responsabilidade de defender e alimentar esses recursos naturais insubstituíveis e de passá-los adiante à geração seguinte, sem danificá-los [...]. 
A gestão dos recursos naturais deve considerar o processo interativo entre o homem e a natureza. Nesse sentido, Drew (1986) afirma:

\begin{abstract}
A interação existente no meio ambiente natural e como a mudança em um elemento pode iniciar alterações em cadeia atingindo todo o sistema. Desses sistemas o mais vulnerável a ação do homem é o que envolve os seres vivos (ecossistema), alterando a cobertura vegetal, topografia do solo, qualidade do ar e da água, alem de interferir desastrosamente nos ciclos de muitos elementos naturais como nitrogênio, fósforo, potássio, sódio. Por outro lado, vários são os exemplos de sucesso de parcerias entre o homem e a natureza.
\end{abstract}

Esse processo interativo e sistêmico deve analisar como vem sendo utilizado os bens comuns à humanidade, que em princípio não pertencem particularmente a ninguém (florestas naturais, águas continentais e marinhas, praias, paisagens, atmosfera, fauna selvagem), a variabilidade ecológica, as incertezas científicas, e os riscos de danos comensurados a uma escala global como a perda da biodiversidade e o efeito "estufa".

A capacidade do Planeta Terra para sustentar a vida tem sido comprometida em escala crescente com o passar do tempo e o aumento da população humana. A degradação ambiental em termos globais tem aumentado consideravelmente nos últimos 200 anos. Estima-se que anualmente de 60 a 70.000 $\mathrm{km}^{2}$ de terras no mundo, são degradadas pelo processo erosivo, tornando-se improdutivas. A erosão laminar do solo diminuiu em três vezes a capacidade das grandes bacias hidrográficas e oito vezes a capacidade dos pequenos cursos d'água, enquanto o consumo de água potável cresceu de 100 para 3.600 quilômetros cúbicos por ano. Cerca de $180.000 \mathrm{Km}^{2}$ de florestas tropicais desaparecem todo ano comprometendo seriamente a biodiversidade (UICN; PNUMA, 1991).

O modelo atual de sociedade estimula o consumo, a industrialização e o gasto de energia. O sistema produtivo e seus produtos geram grandes volumes de resíduos sólidos, efluentes líquidos (que poluem o solo e a água) e emissões gasosas, como o metano, o dióxido de carbono, o clorofluorcarboneto (CFC), que interferem na camada de ozônio produzindo o efeito estufa e $\mathrm{CO}^{2}$ que causa a chuva ácida. 
Em contrapartida, nos últimos anos tem aumentado consideravelmente a consciência ecológica em todo o mundo. Cada vez mais, aumenta o número de pessoas que acreditam serem os recursos naturais finitos e que seu uso deve ser feito de forma racional e parcimoniosa e que o desenvolvimento só pode ser pleno se for baseado na sustentabilidade ecológica.

Vários segmentos sociais percebem a necessidade de mudanças de hábitos. Entendem que fazem parte de um sistema de vidas interdependentes e que a decisão de um grupo certamente afetará outras sociedades, futuras gerações e outras espécies. Estão saindo de uma postura reflexiva e assumindo atitudes coerentes com este pensamento sistêmico.

Uma nova e crescente classe de consumidores está valorizando mais os produtos e serviços ambientalmente corretos, que de uma forma ou de outra não agridem a natureza ou que promovem a sua conservação. Estes consumidores estão dispostos a pagar por isto, mas cobram novas posturas das organizações e o comportamento ético para a vida sustentável. Quando o mercado perceber que o efeito cumulativo de ações pró-ativas em defesa do desenvolvimento sustentado pode modificar os padrões de consumo de recursos e as atitudes dos empresários com relação ao meio ambiente, muitas conquistas serão alcançadas.

Assim, obriga-se a maiores investimentos na pesquisa de sistemas de produção e de produtos que consumam menos energia e causem menos poluição ambiental. É o caso da substituição do gás CFC (clorofluorcarboneto) nos refrigeradores, por outro não poluente, da eliminação da chamada "energia de espera" dos equipamentos eletrônicos, da substituição dos combustíveis fósseis, da indústria da reciclagem (reaproveitamento do material) e reuso (utilização do mesmo produto mais de uma vez) e outros.

Hoje, a adoção na administração da organização de um Programa de Controle da Qualidade Total (TQC) puro e simples, já não é suficiente. Isto porque o ambiente da empresa tornou-se muito mais complexo e o mercado mais exigente. A empresa meramente comercial, mercantilista, passou a ter as características de uma unidade sócio-política com a inclusão de aspectos como qualidade de vida, 
relacionamento social, respeito ao consumidor e o seu inter-relacionamento com o meio ambiente. A esse respeito, Valle (1991) defende:

A idéia da competitividade nas empresas não ser incompatível com a
proteção ambiental [...] que considera estar a Qualidade Ambiental
intimamente ligada à Qualidade Total. Reafirma a necessidade que tem as
empresas para assegurar sua posição no mercado ou se tornarem
competitivas, de assumirem mudanças internas por meio da
conscientização ambiental.

A adoção das normas ISO 9000 com relação à qualidade total e da série ISO 14000 (ABNT, 1996), que trata das relações entre o setor produtivo e o meio ambiente, tem sido a maneira de adequar o sistema gerencial das organizações às novas exigências do mercado. As empresas passaram da atitude defensiva e reativa com relação à proteção ambiental para uma atitude pró-ativa e criativa, antecipandose aos reclamos dos consumidores e imposições da legislação.

No setor de serviços e particularmente no hoteleiro, há também a tendência da adoção das novas abordagens criativas. O primeiro hotel no mundo a conquistar esta certificação foi o Crowne Plaza Hotel HEIDELBERG na Alemanha. No Brasil o Grande Hotel São Pedro, empresa-pedagógica do Senac São Paulo foi o primeiro hotel-escola do País a ter o seu sistema de gestão ambiental certificado pelas Normas Internacionais ISO 14000 (ABNT, 1996).

A indústria do turismo em geral e o setor hoteleiro em particular, deve ter sua parcela de responsabilidade em fazer da ética e do desenvolvimento sustentável, partes integrantes de suas metas, já que dependem da qualidade do meio ambiente para o seu crescimento.

Faz-se necessário, estimular as boas iniciativas empresariais visando à conservação dos recursos naturais, a beleza cênica e a sustentabilidade. Tais estímulos poderiam vir com o aumento dos consumidores que valorizam estas ações pagando melhores preços e do poder público por meio de renúncias fiscais ou auxílio na infra-estrutura.

A International Hotels Environment Initiative - IHEI, que desenvolve para a indústria hoteleira internacional um programa que beneficia seus associados e o meio ambiente, descreve seis razões para a adesão dos hotéis ao movimento ecológico (IHEI, 2008): 
1. Redução dos custos: aumentando a eficiência e reduzindo o desperdício. Por exemplo, o Hotel Inter-Continental, em Sydney, economizou em apenas um ano 24.000 dólares diminuindo a temperatura da água da lavanderia de $90^{\circ} \mathrm{C}$ para $60^{\circ} \mathrm{C}$ sem perda da qualidade dos serviços.

2. Antecipação à pressão do mercado: segundo a IHEI, tem aumentado o número de clientes que optam pelos hotéis com políticas ambientais.

3. Motivação dos colaboradores: que associam os assuntos ambientais a empresas responsáveis, com administração dinâmica e avançada.

4. Melhoria da imagem: ao associar o nome ou logotipo do hotel a eventos, publicações e ações de proteção ambiental.

5. Prevenção de riscos: crescem o número de bancos que consideram o desempenho ambiental do hotel antes de conceder empréstimos.

6. Conformidade com a legislação: um sistema de classificação de hospedagem que leva em conta a variável ambiental e suas nuances, poderá contribuir com a melhoria do desempenho empresarial em relação ao meio ambiente, na medida em que se torne instrumento confiável de orientação ao consumidor e parâmetro de avaliação para os órgãos de classe, governamentais e fiscalizadores. O setor hoteleiro é responsável direto pelo desenvolvimento do turismo.

A atividade turística, ao lado da construção civil, é a que mais gera empregos, tributos e movimento na economia. E por outro lado, a chamada indústria sem chaminés, pode ser também a atividade econômica com menos agressão ao meio ambiente (IHEI, 2008).

É no contexto do desemprego, da crise econômica e dos conflitos sociais, que o turismo pode significar melhor distribuição de renda e crescimento econômico sem pressionar os recursos naturais, isto é, desenvolvimento sustentável. Por isso, entidades como a Confederação Nacional do Comércio (CNC) por meio da Associação Brasileira das Entidades de Hospedagem, Alimentação e Turismo (ABRESI), Instituto Brasileiro de Turismo (EMBRATUR), Serviço Brasileiro de Apoio 
às Micro e Pequenas Empresas (SEBRAE), têm promovido a criação de instrumentos de valorização e profissionalização do turismo brasileiro.

Considerando que este setor envolve características particulares, diferente do setor de manufatura, notadamente no tocante à relação direta entre o prestador de serviços (produtos) e o hóspede ou turista (consumidor final), e o fato do produto ser consumido no local de origem, obrigando o deslocamento do consumidor, faz-se necessário um estudo detalhado destas relações e os possíveis vínculos com o meio ambiente. 


\section{OBJETO DE ESTUDO}

O objeto deste projeto e a implantação de uma Pousada Ecológica na Chapada Imperial que será uma alternativa para a sustentabilidade local e a consolidação do Ecoturismo no Distrito Federal. A implantação de um empreendimento hoteleiro nos padrões sustentáveis de consumo é considerada fator relevante para o desenvolvimento sustentável da Chapada Imperial e da microregião.

\subsection{Organização Pesquisada}

A organização objeto de pesquisa é a Pousada Ecológica Chapada Imperial. O local vem sendo preservado desde 1985, constituindo-se em uma reserva natural (Figura 1). Tem formação bastante diversificada, reúne áreas de cerrado "senso strictu", cerrado rupestre, cerradão, matas mesofíticas (interflúvio e calcária), mata de galeria, campo cerrado, campo de murundum, campo sujo, campo limpo, campo úmido, brejo e veredas.

\section{Figura 1 - Chapada Imperial}

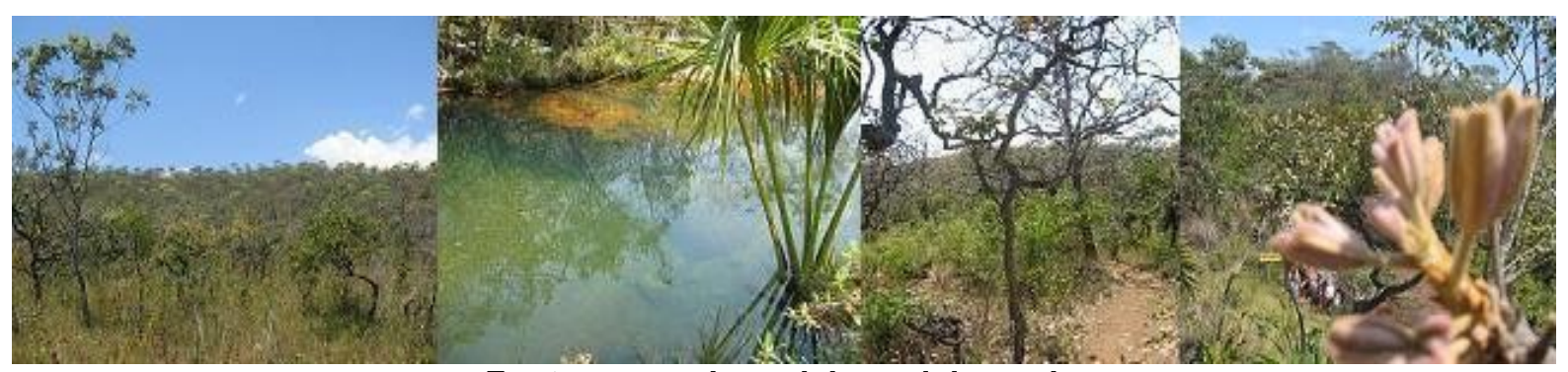

Fonte: www.chapadaimperial.com.br

A Chapada possui uma área aproximada de 4800 ha e está localizada na APA de Cafuringa - Área de Proteção Ambiental. Esta propriedade é, hoje, a maior área particular preservada dentro do DF (Figura 2). Tem localização privilegiada e encontra-se no ponto mais alto do Distrito Federal, 1342 metros. Distancia de $50 \mathrm{~km}$ do centro da capital federal (CHAPADA IMPERIAL, 2008). 
Figura 2 - Chapada Imperial

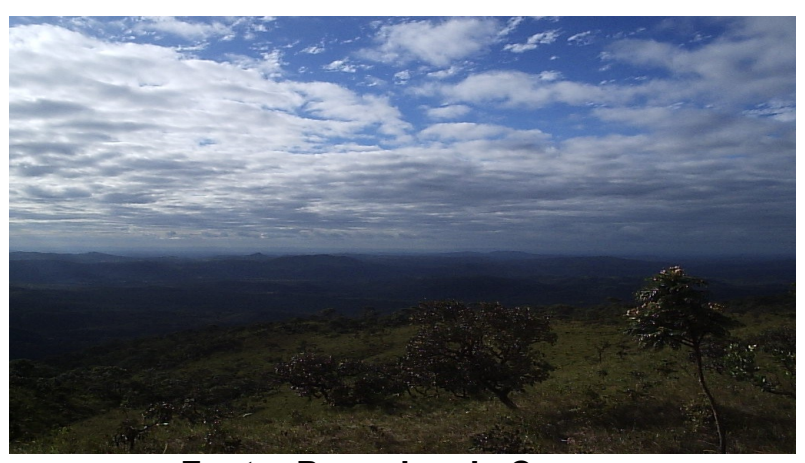

Fonte: Pesquisa de Campo

Inúmeros animais fazem da Chapada Imperial seu habitat natural e, entre eles, muitos ameaçados de extinção, tais como onça, lobo-guará, tamanduábandeira, tatu-canastra, tornando-a um santuário ecológico (Figura 3) (CHAPADA IMPERIAL, disponível em; www.chapadaimperial.com.br).

Figura 3 - Chapada Imperial

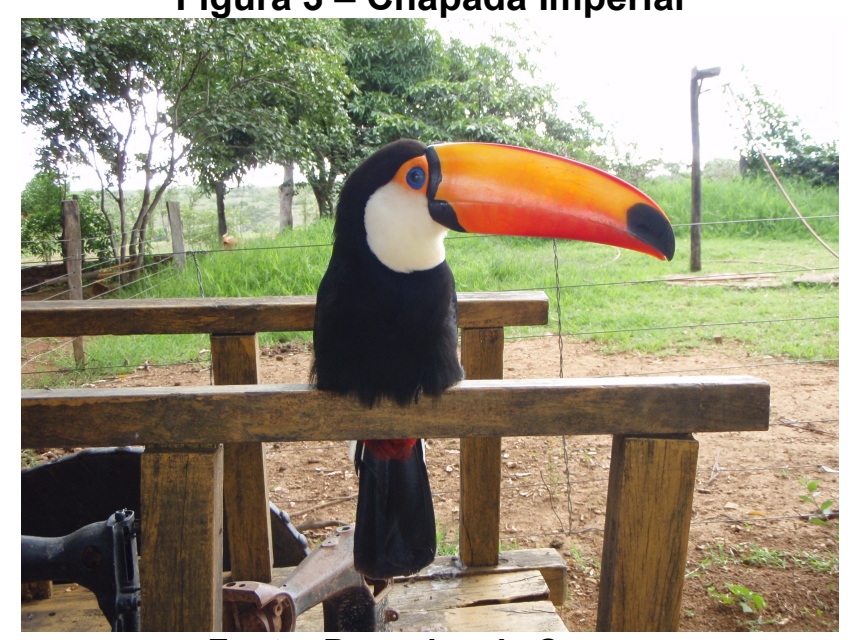

Fonte: Pesquisa de Campo

A área possui formações rochosas e canions em terrenos acidentados com cerca de $95 \%$ íntegros. São terrenos que se situam sobre rochas com mais de um bilhão de anos e cobertos por vegetação típica dos cerrados que se destaca como o segundo bioma brasileiro em extensão territorial e extremamente rico do ponto de vista botânico.

O projeto Chapada Imperial é baseado da idéia de desenvolvimento sustentável. O turismo foi à solução encontrada para manter a preservação do lugar. 
Os trabalhadores da fazenda são a priori da comunidade local com capacitação periódica, sobre o ofício e sobre a preservação do cerrado e da própria comunidade.

Há vários projetos voltados para o desenvolvimento sustentável em execução, tais como: Produção artesanal de doces, licores e conservas em parceria com as mulheres da região. O projeto Bicho Livre em parceria com o IBAMA, onde são realizadas solturas de animais silvestres com o acompanhamento $\mathrm{e}$ monitoramento do IBAMA. O Projeto de Inclusão com crianças carentes de abrigos e escolas que são recebidos na reserva a custo zero para elas aprenderem o respeito à natureza e a vida de uma forma geral. O projeto do Museu Eco-Histórico de resgate da cultura rural local com seus modos de vida, ofícios e interação com a vida silvestre. O banheiro verde, construído para servir de modelo de aproveitamento de lixo, além de telha de tetra park reciclada, lâmpadas de garrafas pet, fossa ecológica e coletores solares com pets e tetra parks para aquecimento da água do chuveiro. Dentre as principais atrações da Chapada Imperial, encontram-se (CHAPADA IMPERIAL, 2008):

\section{a) Trekking}

As caminhadas são realizados pelas trilhas naturais feitas pelo gado em suas andanças, após as nascentes e às margens do Ribeirão Dois Irmãos que, juntamente com outras 35 nascentes e a Lagoinha da Chegança (1335 m, água mais alta do DF) formam o complexo hídrico da Chapada Imperial.

Margeando o ribeirão Dois Irmãos, água cristalina e potável, os visitantes conhecem várias fitofisionomias do cerrado e visitam várias cachoeiras de tamanhos variados que se encontram no percurso, seja ele o da trilha leve (1 e 2), levemoderada ou moderada.

As visitas são feitas em grupos, acompanhadas por guias locais que ministram aula de educação ambiental além de oferecer segurança aos visitantes. Saída de local e hora a combinar.

\section{b) Trilhas}

São três trilhas específicas demarcadas pelo grau de dificuldade: 
a. Trilha leve: para adultos e crianças a partir de três anos. Caminhada tranqüila de $1 \mathrm{~km}$ em $2 \mathrm{~h}$ num desnível de aproximadamente $30 \mathrm{~m}$, com paradas para banhos e pic-nic. Visita a 4 poços de água cristalina, 3 cachoeiras e 2 mirantes. Educação ambiental conhecendo cinco vegetações de cerrado.

b. Trilha leve-moderada: para adultos e crianças a partir de 7 anos. Atividade com tempo aproximado de $3 \mathrm{~h} 30$ em $3 \mathrm{~km}$ de caminhada num desnível de $200 \mathrm{~m}$ aproximadamente, com paradas para banhos e pic-nic. Visita 12 poços de água cristalina, 9 cachoeiras, 3 mirantes e um 1 sumidouro. Educação ambiental conhecendo sete vegetações de cerrado: vereda, mata de galeria, campo úmido, campo sujo, campo limpo, cerrado censo stricto, e campo rupestre.

c. Trilha moderada: pra adultos e crianças a partir de 7 anos. Caminhada de 4,5 km em aproximadamente $5 \mathrm{~h}$ num desnível de 400 m, com paradas para banhos e pic-nic. Retorno no transporte interno, "pau-de-arara" em estrada de $3 \mathrm{~km}$. Visita a diversos poços de água cristalina e cachoeiras perfazendo um total de 30 pontos visitáveis. Educação ambiental conhecendo mais de oito vegetações de cerrado.

\section{c) Rapel}

É uma técnica usada para efetuar uma descida vertical com o auxílio de uma corda (Figura 4).

Figura 4 - Chapada Imperial

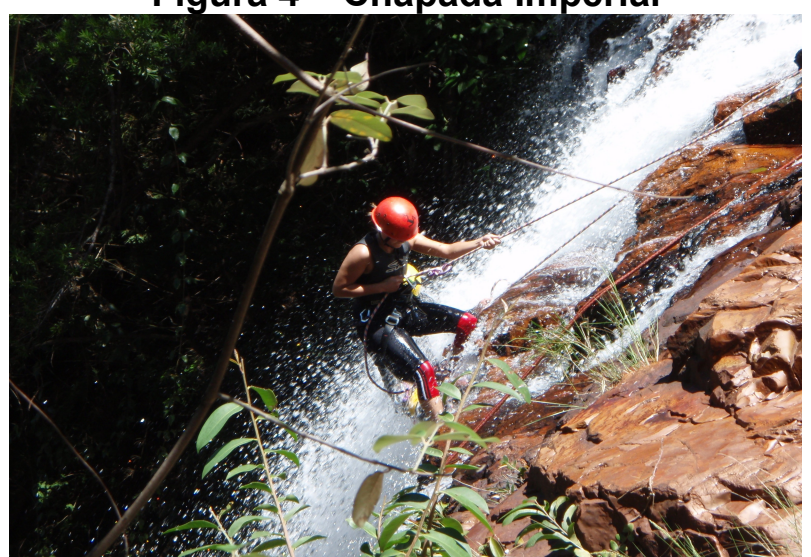

Fonte: Pesquisa de Campo 


\section{d) Mountain Bike}

Surgiu no final dos anos 70, em trilhas das montanhas da Califórnia EUA. "Eram basicamente bikers de estrada, que começaram a buscar um novo estilo no ciclismo, uma alternativa às do asfalto" (CHAPADA IMPERIAL, 2008).

\section{e) Arvorismo ou arborismo}

Consiste basicamente em transpor obstáculos de uma árvore a outra. Essa prática exige equipamentos de segurança, tais como: cadeirinha, costuras, roldanas e roupas especiais. Hoje com a expansão do esporte, existem pistas montadas com níveis de dificuldades diferenciados. Na Chapada Imperial há uma pista considerada fácil, na qual crianças a partir dos treze anos podem participar.

\section{f) Camping}

A Chapada Imperial conta com uma área de camping ótima infraestrutura.

\section{g) Educação Ambiental}

A Educação Ambiental é ministrada pelos guias durante o percurso das atividades que além de comentar as diversas vegetações que compõem o cerrado, explica a relação ideal do homem com o meio.

\section{h) Programa Pedagógico:}

A Chapada Imperial contribui com o Programa Pedagógico Rural que tem os seguintes objetivos:

- Elaborar e consolidar o conceito de programa pedagógico voltado para o turismo rural;

- Caracterizar os potenciais e aptidões locais a serem destacadas no programa pedagógico;

- Elaborar o programa pedagógico como produto estratégico das propriedades participantes; 
- Diversificar o público visitante por meio da elaboração de um programa pedagógico voltado para a educação formal e não-formal;

- Indicar material didático de apoio às atividades do programa pedagógico;

- Elaborar modelo de Guia Promocional do Programa Pedagógico;

- Capacitar proprietários e envolvidos na realização das atividades do programa.

i) Rota das Árvores

Esse projeto tem o objetivo de

Contribuir para o enriquecimento da proposta educativa de empreendimentos do turismo rural por meio do resgate e da valorização do patrimônio natural destes locais com foco na vegetação [...] a realização de um trabalho de levantamento e identificação da vegetação e de espécies arbóreas existentes nos principais circuitos das propriedades participantes (CHAPADA IMPERIAL, 2008).

A Chapada Imperial possui vasto recurso hídrico (Figuras 5, 6 e 7):

- 55 nascentes na cheia e 26 na seca;

- Bacia do Tocantins/Araguaia (Ribeirão Dois Irmão; Rio do Sal, Rio Maranhão; Rio Tocantins até a Foz do Rio Amazonas);

- Nascentes do ribeirão Dois Irmãos totalmente dentro da reserva;

- Ribeirão Dois Irmãos, água cristalina, potável. A vazão média situa-se entre 150 e $200 \mathrm{~m}^{3} / \mathrm{s}$, gerando uma potência de $55 \mathrm{kw}$ (kilowatt) com capacidade para suprir cerca de 160 residências de $100 \mathrm{~m} 2$ de área (estudo de vazão 1996 - eng. Marco Motta);

- Qualidade da água na C.I. “excelente” (estudos da CAESB). 
Figura 5 - Cascatinhas

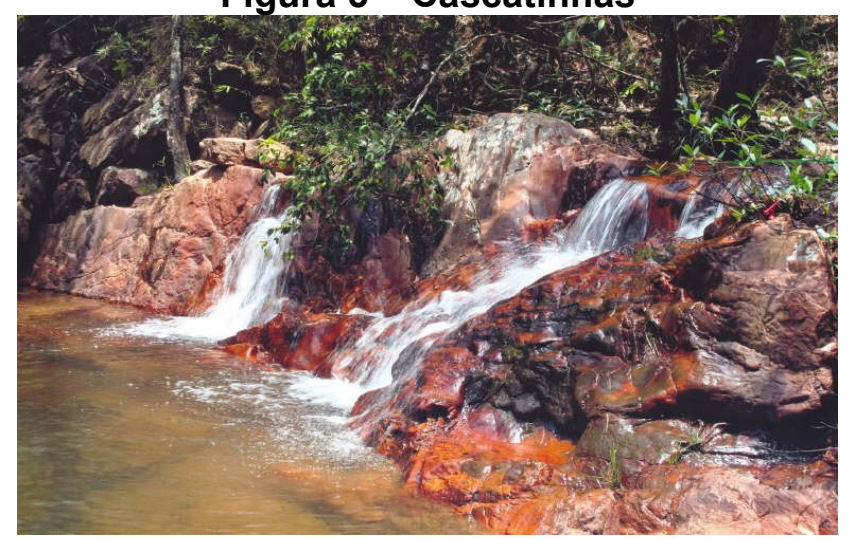

Fonte: http://www.chapadaimperial.com.br

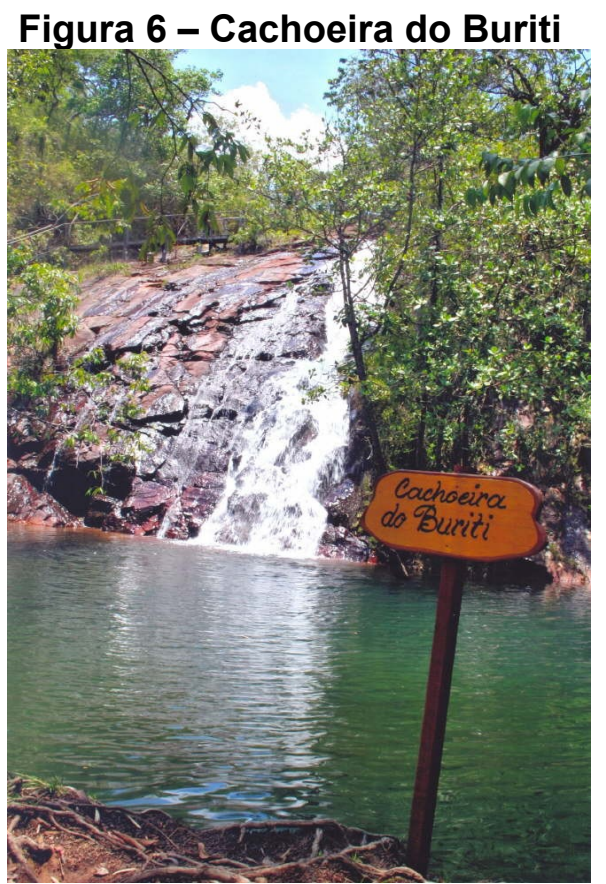

Fonte: http://www.chapadaimperial.com.br
Figura 7 - Chapada Imperial

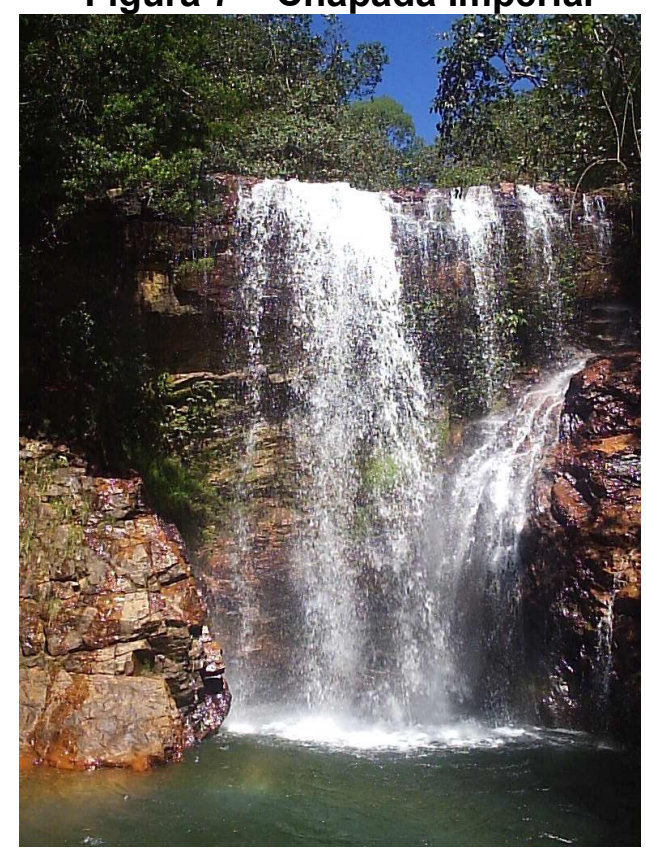

Fonte: Pesquisa de Campo

A Chapada Imperial dispõe de ampla infra-estrutura com atrações diversas, tais como:

- 33 cachoeiras naturais;

- 95\% da área preservada;

- Trilha ecológica;

- Centro de Convenções;

- Criatório Conservasionista;

- Chalés;

- Mini-pôneis;

- Educação Ambiental; 
- Centro de visitantes;

- Banheiros;

- Refeitório com fogão a lenha;

- Galpão aberto com capacidade para 100 pessoas sentadas;

- Horta orgânica;

- Museu eco-histórico em fase de catalogação;

- Pomar de mangueiras centenárias;

- Redários;

- Segurança;

- Vendola com produtos locais e artesanato;

- Confraternizações;

- Festas temáticas e eventos: festas de aniversários infantis com temas rurais; festas juninas; festas folclóricas;

- Festa do "Raloim Caipira" (folclórico);

- Safári fotográfico;

- Corrida de orientação.

Todas as frentes de trabalho desenvolvidas e praticadas pela Chapada Imperial têm preocupação com o resgate cultural, com a valorização da comunidade e com o respeito ao meio ambiente, além de estarem dentro do esquema de segurança e dentro da ideologia da reserva de resgate cultural e comunitário e respeito ao meio ambiente.

\subsection{Estrutura da Chapada Imperial}

A atividade de ecoturismo é desenvolvida utilizando uma estrutura de concepção simples e arraigada ao ambiente agrário que é típico da propriedade rural onde se desenvolve o empreendimento (PETRILLO; BORBA, p. 76 2002).

\subsubsection{O planejamento}

O planejamento turístico empregado conforme a tipologia do ecoturismo é projetado de acordo com a necessidade de encaminhamento e atendimento do fluxo de turistas que se localizam dentro dos limites da propriedade Dois Irmãos. Uma Estrada de terra fornece acesso à área do receptivo, que pode ser compreendida 
como uma antiga casa de funcionários adequada à realidade da atividade. Trata-se de uma construção em alvenaria convencional, com varandas e área de alimentação, conta com empório de artesanato e souvenirs.

Existem várias árvores antigas e de grande porte ao redor e nas adjacências da construção, fornecendo uma considerável área sombreada em torno da construção, o que denota a situação de núcleo remanescente da fazenda. Esta ampla área sombreada fornece toda uma gama de atrativos de descontração, dentre os quais uma área para redes de balanço, casa da árvore, tirolesa, mesas sombreadas.

Estas características levaram à definição deste local como área núcleo do empreendimento, onde se concentra a infra-estrutura central, para a qual todo o fluxo de chegada de turistas é encaminhado e redirecionado para o sistema de trilhas, para posterior retorno ao receptivo, alimentação, descanso, descontração e saída do empreendimento.

Ainda como infra-estrutura de apoio, a propriedade conta com quatro estradas denominadas de "resgates", que fornecem acesso ao fundo de vale do Ribeirão Dois Irmãos, com o intuito de dar a possibilidade de salvamento e apoio motorizado a emergências. O investimento neste tipo de logística operacional é fundamental para o funcionamento seguro do empreendimento. 


\section{AÇÕES E RESULTADOS A ALCANÇAR}

\subsection{O Projeto}

A estrutura de visitação implantada na propriedade tem se mostrado promissora com uma demanda espontânea por hospedagem. Desta forma, inicia-se o planejamento para implantação de produtos turísticos inerentes, agregando valor ao produto turístico existente, gerando maior oportunidade de emprego e renda, aumentando as condições de exploração sustentável dos recursos naturais.

Após vários levantamentos de campo, avaliações e pesquisas de tipologias de hospedagem existentes, chegou-se à tipologia que mais se adequou à realidade da propriedade: os chalés.

A Pousada Ecológica Chapada Imperial, será um meio de hospedagem de pequeno porte, que oferecerá alojamento e alimentação básicos, mas de qualidade, para o turista que queira se hospedar, no mínimo por uma noite na Chapada Imperial, de forma que a arquitetura, a decoração e a prestação de serviço, estarão relacionados à responsabilidade ambiental, e à realidade da região.

\subsubsection{Estrutura Física}

Como a realidade da Fazenda Dois Irmãos é a preservação do patrimônio natural com a temática de uma exploração sustentável, será desenvolvido um sistema de hospedagem que utilize tecnologias limpas não perdendo o conforto e aconchego de uma Pousada de Charme.

As construções podem ser definidas como mini-chalés, com espaço aproximado de $35 \mathrm{~m}^{2}$ totais, cumeeira de $2,5 \mathrm{~m}$ de altura, compostos de um espaço dividido em dormitório e varanda e um pequeno banheiro com $4 \mathrm{~m}^{2}$ incluído na área, podendo utilizar madeira licenciada e alvenaria como material base de construção. 
Acredita-se que um número inicial e provisório para iniciar tais construções deve ser um marco de pelo menos 10 (dez) unidades habitacionais. Entende-se que, por se tratar de construções consideradas do tipo simples - isto é, não se pretende que possuam um estilo comercial nem residencial sofisticado, mas sim um estilo "rústico" - o que certamente reduz bastante os custos de construção.

Cada chalé terá a seguinte estrutura: 1 cama de casal, 1 sofá cama, 1 frigobar, 1 TV 20", 2 mesas de cabeceira, 2 abajurs, 1 mesa de 2 lugares, 2 cadeiras, 1 armário rústico de madeira, 2 quadros decorativos, 1 cortina.

Vale dizer que tais construções já fazem parte de um conjunto de proposta deste estudo, por entender que a área, além de requerer, comporta com facilidade tais equipamentos.

Tabela 1 - Construção de Chalé

\begin{tabular}{|l|c|c|c|}
\hline Qtde & Descrição & Valor $/ \mathrm{m}^{2}$ & Valor total \\
\hline 10 & $\begin{array}{l}\text { Construção de chalé de } 35 \mathrm{~m}^{2} \text { e pé direito } \\
\text { de } 2,5 \mathrm{~m} \text {. Cada chalé terá } 01 \text { varanda } \\
\text { medindo } 1,5 \mathrm{~m} \times 5 \mathrm{~m}, 01 \text { quarto medindo } \\
5 \mathrm{~m} \times 3,5 \mathrm{~m} \text { e } 01 \text { banheiro medindo } 2 \mathrm{~m} \times 5 \mathrm{~m} .\end{array}$ & & $\mathrm{R} \$ 175.000,00$ \\
& Sistema de coleta de resíduos sólidos. & & \\
\hline
\end{tabular}

Fonte: SINDUSCON/DF. Disponível em: www.sinduscon.df.com.br, Acesso em 25 jul. 2008

É importante afirmar que o ordenamento territorial, traduzido para critérios de espacialidade local - no qual se consideram os princípios da simplicidade, do lazer, do baixo custo, do prazer, nesse conjunto considerando um espírito de instalações simples e, para não dizer "modestas" - é fundamental para o planejamento de sustentabilidade do sistema de hospedagem que ele seja, do ponto de vista deste projeto, baseado na sugestão de construção simples.

\subsubsection{Visão}

Ser uma referência na Preservação Ambiental na região de Brazlândia-DF. 


\subsubsection{Missão}

Promover a preservação ambiental por meio do turismo rural e ecológico, agregando valores a produtos e serviços, resgatando e promovendo o patrimônio cultural e natural da comunidade.

\subsubsection{Valores}

Busca de excelência, criatividade e inovação na preservação do meio ambiente, satisfação dos clientes e colaboradores e valorização das pessoas.

\subsubsection{Ações para implantação do Projeto Pousada Ecológica Chapada Imperial.}

A preocupação em reduzir ao máximo os impactos ambientais da construção civil - que responde pelo uso de $40 \%$ de todas as matérias-primas, $60 \%$ da madeira extraída, $40 \%$ da energia consumida e $16 \%$ da água potável - justificaram o aparecimento do greenbuilding, em outros termos "natural building", eco-construção, bioconstrução (TRIGUEIRO, 2005, p. 94).

Para a construção do Projeto Pousada Ecológica Chapada Imperial serão utilizadas matérias primas de baixo impacto, as paredes serão construídas com tijolos de adobe, superadobe (terra ensacada). Esse tipo de construção é ideal para o aproveitamento dos recursos naturais disponíveis. O equilíbrio da climatização interna, com um rendimento térmico que garante temperaturas entre 20 e $25^{\circ} \mathrm{C} \mathrm{em}$ qualquer época do ano, torna a estada muito agradável, além de esteticamente contribuir para que a construção se integre a paisagem natural do local (IPEC; disponível em: www.ecocentro.org).

A madeira que será utilizada na construção, portas e janelas, e na decoração dos chalés será liberada por órgãos fiscalizadores competentes (IBAMA disponível em: www.ibama.gov.br), ou seja, material ecologicamente correto. Será utilizado também o bambu para finalidades específicas como a de substituição do aço, concreto e principalmente da madeira. Devido seu baixo custo, valor estético e completamente renovável é um material alternativo importante, lembrando que o 
bambu precisa passar por tratamento de cozimento especial para aumentar sua resistência (IPEC; disponível em: www.ecocentro.org).

Para o revestimento das paredes da construção e tintas, serão utilizadas as técnicas naturais a base de terra crua.

Para o teto dos chalés da Pousada serão utilizadas telhas fabricadas de embalagens longa-vida (tetra pack) ou resíduos de papel reciclável.

Essas telhas favorecem o escoamento da água da chuva que também pode ser aproveitada na captação, para abastecimento da pousada.

Nos banheiros serão utilizados o sistema de Ecofossas ou Biodigestor que se constitui em uma cisterna fechada, onde na ausência de oxigênio, as próprias bactérias presentes no esgoto doméstico digerem a matéria orgânica. Esse sistema dispensa a utilização de produtos químicos (CPRATA: disponível em www.cprata.com.br).

O abastecimento de água da Pousada será feito por bombas de sucção já existente no local. A água utilizada nos banhos será tratada, armazenada e reutilizada na limpeza dos Chalés.

Para uso de água quente será utilizado o sistema de aquecimento solar. Os aquecedores economizam em até $80 \%$ de energia elétrica. (HELIOTEK: disponível em: www.heliotek.com.br).

A construção dos chalés será planejada com design e arquitetura de Charme e utilização dos vidros e placas refletoras que geralmente ficam bem expostas nos telhados, para a captação e distribuição da luz solar.

Levando-se em consideração a responsabilidade sócioambiental. Serão escolhidos artigos artesanais na decoração, de preferência produzidos pela comunidade da região e manufaturados com recursos locais, valorizando a arte regional. Os recicláveis também têm grande utilidade neste aspecto, pois proporcionarão aos hóspedes um maior conhecimento da utilização desses recursos. 


\subsection{Resultados Esperados}

Com a implantação da Pousada Ecológica Chapada Imperial, vários resultados, baseado da sustentabilidade ambiental, social e econômica serão almejado, pois os mesmos contribuirão para o sucesso do empreendimento.

\subsubsection{Planejamento social}

Este projeto constatou a influência que causará às comunidades locais e do entorno com a implantação de uma Pousada Ecológica na Chapada Imperial. Com o objetivo de deixar clara essas influencias o assunto será tratado em tópicos.

- Saúde: Os treinamentos que serão oferecidos pela empresa de Recursos Humanos contratada, com o apoio do RURALTUR - Sindicato de Turismo Rural e Ecológico do DF os colaboradores e seus familiares e amigos próximos terão informações sobre ao acesso aos meios de informação e a atendimento médico. Informações básicas de higiene e saúde que serão adquiridas e repassadas às pessoas de convívio próximo, o que representarão um aumento na qualidade de vida dos envolvidos. Providencias simples, mas que significam muito para a saúde, passarão a ser tomadas. Como, por exemplo, lavar as mãos após o uso do sanitário, lavar e desinfetar, armazenar corretamente e verificar o prazo de validade dos alimentos, ingerir somente água filtrada ou fervida.

- Educação: No sentido de melhorar o sistema de educação regional, bem como facilitar o acesso da população à escola também será uma conquista. Um bom exemplo o Programa Pedagógico que já existes na Chapada Imperial que envolve toda a comunidade local e do entorno.

- Desenvolvimento Local: A valorização do artesanato local, por meio da agregação de valores, significa muito para as comunidades locais. Muitas famílias têm os seus rendimentos aumentados devido à especialização em criação de produção de artesanatos, esse é, sem dúvida, um fato relevante para o desenvolvimento local. Será criado na Chapada Imperial um espaço 
para criação e comercialização de produtos artesanais tais como: objetos decorativos em bambu, licor de frutas da terra, queijo frescal, doces, geléias e etc., para aumentar a renda da comunidade local.

\subsubsection{Planejamento ambiental}

A pousada ecológica será implementada na Chapada Imperial, menos de $50 \mathrm{~km}$ do centro de Brasília, no ponto mais alto do Distrito Federal $(1.347 \mathrm{~m}) \mathrm{na}$ Fazenda Dois Irmãos, na rodovia DF-220, Km 9 , no município de Brazlândia.

Com o intuito de se saber se determinado terreno é adequado à implantação de determinado empreendimento hoteleiro é preciso verificar alguns critérios de macrolocalização necessários ao tipo de hotel prefixado. Isto é, se a posição relativa do terreno oferece as vantagens de localização requeridas, inclusive no que diz respeito às redes de infra-estrutura urbana (ANDRADE, 2002).

Inicialmente, faz-se necessário verificar a legislação municipal de zoneamento e uso do solo incidente sobre a área. É preciso saber se ela permite o uso hoteleiro e quais são os índices de ocupação e utilização admitidos, determinando, entre ouros, se a pousada terá um uso compatível com a legislação e a área que poderá ser construída (ANDRADE, 2002).

Segundo Nelson Andrade (2002), é necessário avaliar as condições físicas do terreno:

- Declividade: quanto maior, maiores custos com movimento de terra e com obras de contenção.

- Consistência do subsolo: terrenos com baixa resistência exigem fundações mais onerosas.

- Nível do lençol freático: quanto mais alto o lençol freático, mais restrições haverá nas soluções de utilização do subsolo e de fundações.

- Forma física: terrenos com formas regulares favorecem a concepção do projeto. 
Para a elaboração do projeto ambiental da pousada será necessário a contratação de uma empresa, especializada em consultoria ambiental e urbanística para que o solo seja ordenado de acordo com a legislação das APA'S (ÁREAS DE PROTEÇÃO AMBIENTAL) e o empreendimento esteja dentro dos padrões do EIA/RIMA (Estudo de Impacto Ambiental da Secretaria do Meio Ambiente).

\subsubsection{Planejamento econômico financeiro}

Organizar e planejar as finanças são mudanças na cultura dos novos empreendedores. Antigamente, sua cultura era saber que podia sustentar as finanças da empresa trancando suas contas de forma quase intuitiva, bastava conferir entradas e saídas e embolsar os "lucro", hoje, os ciclos de vidas de uma empresa são mais curtos, pois as mudanças tecnológicas, de comunicação e mercadológicas aceleram este processo. O investidor deve então planejar as finanças e seus negócios levando em conta outros fatores, como a época do ano, os compromissos a vencer, os investimentos indispensáveis, a valorização do patrimônio e outros.

O projeto financeiro da Pousada Ecológica foi baseado no modelo de Analise e Planejamento Financeiro para Pequenos Meio de Hospedagens, Aprenda a Empreender do SEBRAE NACIONAL.

Os custos necessários à implantação da Pousada Ecológica na Chapada Imperial compreendem um valor total $\mathrm{R} \$ 295.747,44$ conforme se discrimina na Tabela3 e nas demais tabelas descrevem como esse Capital será investido e qual o seu tempo de retorno. 


\subsubsection{Tabelas financeiras}

Segundo Almeida (2003), os planejamentos financeiros necessários à implantação de qualquer empreendimento, e no caso especial da Chapada Imperial, passam (ou deveriam) passar, pelas sugestões de planilhas que o mesmo faz. E nesse sentido, adotou-se para este Projeto.

Tabela 2 - Proposta Inicial de Móveis e Equipamentos

\begin{tabular}{|r|l|r|r|}
\hline & PROPOSTA INICIAL DE MÓVEIS E EQUIPAMENTOS & & \\
\hline QTD & ITENS & VALOR UNIT. & VALOR TOTAL \\
\hline 10 & lamas box casal & 700,00 & $7.000,00$ \\
\hline 10 & sofás cama & 380,00 & $3.800,00$ \\
\hline 10 & Frigobar & 380,00 & $3.800,00$ \\
\hline 10 & TV 20" & 350,00 & $3.500,00$ \\
\hline 20 & lesas de cabeceiras & 40,00 & 800,00 \\
\hline 20 & lbajur & 40,00 & 800,00 \\
\hline 10 & lesa de 02 lugares & 80,00 & 800,00 \\
\hline 20 & ladeiras & 30,00 & 600,00 \\
\hline 10 & Armário em cadeira rústica & 780,00 & $7.800,00$ \\
\hline 20 & Quadros decorativos & 80,00 & $1.600,00$ \\
\hline 10 & Cortinas & 150,00 & $1.500,00$ \\
\hline 10 & Aquecedor de água solar & 799,00 & $7.990,00$ \\
\hline 10 & kits de Utensílio de banheiros & 79,00 & 790,00 \\
\hline 1 & Computador & $1.300,00$ & $1.300,00$ \\
\hline 1 & Impressora & 400,00 & 400,00 \\
\hline & TOTAL & & $\mathbf{4 2 . 4 8 0 , 0 0}$ \\
\hline
\end{tabular}

Fonte: Modelo planilhas Manual de Planejamento do autor Manoel Isnard Ribeiro Almeida (2003) 
Tabela 3 - Orçamento de Investimentos Programados

\begin{tabular}{|l|r|}
\hline \multicolumn{2}{|c|}{ Orçamento de Investimentos Programados } \\
\hline \multicolumn{1}{|c|}{ Investimento Pousada Ecológica Chapada Imperial } \\
\hline \multicolumn{1}{|c|}{ Referência } & $\mathbf{R}$ \\
\hline 1. Construção de 10 chalés & $175.000,00$ \\
\hline 2. Equipamentos & $15.290,00$ \\
\hline 3. Móveis, utensílios dos chalés & $24.779,00$ \\
\hline 4. Equipamentos administrativos & $1.700,00$ \\
\hline 5. Estoque inicial de materiais & $5.500,00$ \\
\hline 7. Marketing inicial & $2.306,10$ \\
\hline 8. Consultoria em Estudo Ambiental & $28.000,00$ \\
\hline & $\mathbf{2 5 2 . 5 7 5 , 1 0}$ \\
\hline TOTAL INVESTIMENTO FIXO (PRÉ-OPERACIONAL) & $43.172,34$ \\
\hline Capital de giro inicial & $\mathbf{2 9 5 . 7 4 7 , 4 4}$ \\
\hline INVESTIMENTO TOTAL & \\
\hline
\end{tabular}

\begin{tabular}{|lr|}
\hline & Ciclo Financeiro e Capital de Giro \\
\hline Ciclo Financeiro (meses) & 3 \\
\hline NCGO = $\times($ CF $+60 \%$ CV) & $43.172,34$ \\
\hline CF mensal & $5.973,51$ \\
\hline CV mensal (nível de 50\%) & $14.028,78$ \\
\hline \multicolumn{1}{|c|}{ Fonte: Modelo planilhas Manual de Planejamento do autor Manoel Isnard Ribeiro Almeida (2003) }
\end{tabular}


Tabela 34-Projeções de Depreciação Anual

Investimento Pousada Ecológica Chapada Imperial

\begin{tabular}{|c|c|c|c|c|}
\hline Imobilizado & Vida útil (anos) & Depreciação Anual \% & Valor R\$ & $\begin{array}{c}\text { Depreciação } \\
\text { Anual (R\$) }\end{array}$ \\
\hline Construção dos Chalés & 25 & $4,0 \%$ & $175.000,00$ & $7.000,00$ \\
\hline Equipamentos & 10 & $10,0 \%$ & $15.290,00$ & $1.529,00$ \\
\hline Equipamentos Informática & 6 & $16,7 \%$ & $1.700,00$ & 283,33 \\
\hline Móveis, utensílios dos chalés & 6 & $16,7 \%$ & $24.779,00$ & $4.129,83$ \\
\hline TOTAL GERAL & $\begin{array}{ll} & 16,\end{array}$ & $6,0 \%$ & $216.769,00$ & $12.942,17$ \\
\hline
\end{tabular}

Projeção da Folha de Pagamento Fixa Anual Investimento Pousada Ecológica Chapada Imperial

\begin{tabular}{|c|c|c|c|c|}
\hline Colaborador & Quantidade & Salário Líquido Mensal & Fator Encargos & $\begin{array}{l}\text { Custo Total } \\
\text { Anual (R\$) }\end{array}$ \\
\hline Supervisor & 1 & $\mathrm{R} \$ \quad 900,00$ & 0,7 & $8.460,00$ \\
\hline Atendentes & 1 & 600,00 & 0,6 & $4.920,00$ \\
\hline Camareiras & 2 & $1.200,00$ & 0,6 & $9.840,00$ \\
\hline Auxiliar de Limpeza & 1 & 600,00 & 0,6 & $4.920,00$ \\
\hline TOTAL GERAL & 5 & $3.300,00$ & & $28.140,00$ \\
\hline
\end{tabular}

Orçamento de Custos Fixos Anuais

Investimento Pousada Ecológica Chapada Imperial

\begin{tabular}{|l|rr|c|}
\hline \multicolumn{1}{|c|}{ Referência } & \multicolumn{2}{c|}{ Valor } & \multicolumn{1}{c|}{$\%$} \\
\hline Salários e encargos fixos (06 funcionários) & $\mathrm{R} \$$ & $28.140,00$ & $39,3 \%$ \\
\hline Pró-labore & $\mathrm{R} \$$ & $4.980,00$ & $6,9 \%$ \\
\hline Depreciação & $\mathrm{R} \$$ & $12.942,17$ & $18,1 \%$ \\
\hline Telefone & $\mathrm{R} \$$ & $2.400,00$ & $3,3 \%$ \\
\hline Contabilidade & $\mathrm{R} \$$ & $4.980,00$ & $6,9 \%$ \\
\hline Uniformes & $\mathrm{R} \$$ & $2.880,00$ & $4,0 \%$ \\
\hline Transporte e alimentação & $\mathrm{R} \$$ & $11.760,00$ & $16,4 \%$ \\
\hline Material de escritório e limpeza & $\mathrm{R} \$$ & $3.600,00$ & $5,0 \%$ \\
\hline TOTAL GERAL & $\mathbf{R} \$$ & $\mathbf{7 1 . 6 8 2 , 1 7}$ & $\mathbf{1 0 0 , 0 \%}$ \\
\hline
\end{tabular}

Fonte: Modelo planilhas Manual de Planejamento do autor Manoel Isnard Ribeiro Almeida (2003) 
Tabela 5 - Orçamento de Custos Variáveis Anuais

\begin{tabular}{|c|c|c|c|c|c|c|c|c|}
\hline Referência & Nível $50 \%$ & \multicolumn{2}{|c|}{ Orçamento $50 \%$} & $\begin{array}{c}\text { Nível } \\
75 \% \\
\end{array}$ & \multicolumn{2}{|c|}{ Orçamento $75 \%$} & $\begin{array}{l}\text { Nível } \\
100 \% \\
\end{array}$ & $\begin{array}{l}\text { Orçamento } \\
100 \%\end{array}$ \\
\hline Manutenção e Conservação & $10 \%$ & $\mathrm{R} \$$ & $23.061,00$ & $4 \%$ & $\mathrm{R} \$$ & $13.836,60$ & $6 \%$ & $\mathrm{R} \$ 27.673,20$ \\
\hline Mão-de-obra variável & $4 \%$ & $\mathrm{R} \$$ & $9.224,40$ & $5 \%$ & $\mathrm{R} \$$ & $17.295,75$ & $6 \%$ & $\mathrm{R} \$ 27.673,20$ \\
\hline $\begin{array}{l}\text { Impostos, tributos e } \\
\text { contribuições }\end{array}$ & $20 \%$ & $\mathrm{R} \$$ & $46.122,00$ & $20 \%$ & $\mathrm{R} \$$ & $69.183,00$ & $20 \%$ & $\mathrm{R} \$ 92.244,00$ \\
\hline Água, esgoto e energia & $18 \%$ & $\mathrm{R} \$$ & $41.509,80$ & $10 \%$ & $\mathrm{R} \$$ & $34.591,50$ & $10 \%$ & $R \$ 46.122,00$ \\
\hline Marketing & $1 \%$ & $\mathrm{R} \$$ & $2.306,10$ & $3 \%$ & $\mathrm{R} \$$ & $10.377,45$ & $3 \%$ & $\mathrm{R} \$ 13.836,60$ \\
\hline $\begin{array}{l}\text { Aquisição de Mercadorias e } \\
\text { Insumos }\end{array}$ & $12 \%$ & $\mathrm{R} \$$ & $27.673,20$ & $11 \%$ & $\mathrm{R} \$$ & $38.050,65$ & $10 \%$ & $\mathrm{R} \$ 46.122,00$ \\
\hline Combustível & $5 \%$ & $\mathrm{R} \$$ & $11.530,50$ & $5 \%$ & $\mathrm{R} \$$ & $17.295,75$ & $5 \%$ & $\mathrm{R} \$ 23.061,00$ \\
\hline Despesa Café da Manhã & $3 \%$ & $\mathrm{R} \$$ & $6.918,30$ & $3 \%$ & $\mathrm{R} \$$ & $10.377,45$ & $4 \%$ & $\mathrm{R} \$ 16.142,70$ \\
\hline TOTAL GERAL & $73 \%$ & $\mathbf{R} \$$ & $168.345,30$ & $61 \%$ & $\mathbf{R} \$$ & $211.008,15$ & $64 \%$ & $\mathrm{R} \$ \mathbf{2 9 2 . 8 7 4 , 7 0}$ \\
\hline FATURAMENTO PREVISTO & $100 \%$ & $\mathbf{R} \$$ & $230.610,00$ & $100 \%$ & $\mathbf{R} \$$ & $345.915,00$ & $100 \%$ & $R \$ 461.220,00$ \\
\hline
\end{tabular}

\begin{tabular}{|c|c|c|}
\hline \multicolumn{3}{|c|}{ CUSTO DIRETO DA VENDA DE MERCADORIAS -Frigobar } \\
\hline Custos Variável Mensais & Projeção & $\%$ \\
\hline CMV & $1.250,00$ & $50,0 \%$ \\
\hline Custo Comercial & 300,00 & $12,0 \%$ \\
\hline Perdas & 75,00 & $3,0 \%$ \\
\hline TOTAL DO CUSTO DIRETO & $1.625,00$ & $65,0 \%$ \\
\hline MÉDIA DE FAT VENDA MERC & $2.500,00$ & $100,0 \%$ \\
\hline Quantidade em estoque & $2.500,00$ & $100,0 \%$ \\
\hline Giro mensal & $50 \%$ & \\
\hline Markup & 2,00 & \\
\hline
\end{tabular}


Tabela 6 - Projeção de Faturamento Anual com Diária da Pousada Ecológica Chapada Imperial

Projeção de Faturamento Mensal com Diárias nos Chalés

\begin{tabular}{|c|c|c|c|c|c|c|}
\hline Diárias (casal) & \multicolumn{2}{|c|}{ CONCORRENTE 1 } & \multicolumn{2}{c|}{ CONCORRENTE 2 } & \multicolumn{2}{c|}{ Pousada } \\
\hline Dias & $2^{\mathrm{a}}$ a $6^{\mathrm{a}}$ & $\mathrm{SAB}, \mathrm{DOM}$ & $2^{\mathrm{a}}$ a $6^{\mathrm{a}}$ & $\mathrm{SAB}, \mathrm{DOM}$ & $2^{\mathrm{a}}$ a $6^{\mathrm{a}}$ & $\mathrm{SAB}, \mathrm{DOM}$ \\
\hline Valores & $\mathrm{R} \$ 180,00$ & $\mathrm{R} \$ 220,00$ & $\mathrm{R} \$ 210,00$ & $\mathrm{R} \$ 250,00$ & $\mathrm{R} \$ 190,00$ & $\mathrm{R} \$ 240,00$ \\
\hline
\end{tabular}

\begin{tabular}{|c|c|c|c|c|c|c|c|c|}
\hline \multicolumn{9}{|c|}{ MÉDIAS DIÁRIAS } \\
\hline DIÁRIAS & $\begin{array}{c}\text { NR DE } \\
\text { QUARTOS }\end{array}$ & SEG & TER & QUA & QUI & SEX & SÁB & DOM \\
\hline TOTAL & 10 & $\mathrm{R} \$ 570,00$ & $\mathrm{R} \$ 570,00$ & $\mathrm{R} \$ 570,00$ & $\mathrm{R} \$ 1.200,00$ & $\mathrm{R} \$ 2.160,00$ & $2.160,00$ & $2.160,00$ \\
\hline
\end{tabular}

\begin{tabular}{|c|c|c|c|}
\hline DIA & ROTATIVIDADE & DIA & ROTATIVIDADE \\
\hline SEGUNDA & $30 \%$ & SEXTA & $90 \%$ \\
\hline TERÇA & $30 \%$ & SAB & $90 \%$ \\
\hline QUARTA & $30 \%$ & DOM & $90 \%$ \\
\hline QUINTA & $50 \%$ & & \\
\hline
\end{tabular}

Projeção de Faturamento Anual com Diárias nos Chalés

\begin{tabular}{|c|c|c|c|}
\hline Capacidade & Nível $50 \%$ & Nível $75 \%$ & Nível $100 \%$ \\
\hline TOTAL GERAL & $\mathrm{R} \$ 225.360,00$ & $\mathrm{R} \$ 338.040,00$ & $\mathrm{R} \$ 450.720,00$ \\
\hline \multicolumn{4}{|c|}{ Projeção de Faturamento Mensal com Frigobar } \\
\hline Referência & Nível $50 \%$ & Nível $75 \%$ & Nível $100 \%$ \\
\hline CMV & $\mathrm{R} \$ 625,00$ & $\mathrm{R} \$ 937,50$ & $\mathrm{R} \$ 1.250,00$ \\
\hline Custo Comercial & $\mathrm{R} \$ 150,00$ & $\mathrm{R} \$ 225,00$ & $\mathrm{R} \$ 300,00$ \\
\hline Perdas & $\mathrm{R} \$ 37,50$ & $\mathrm{R} \$ 56,25$ & $\mathrm{R} \$ 75,00$ \\
\hline TOTAL DO CUSTO DIRETO & $R \$ 812,50$ & $R \$ 1.218,75$ & $R \$ 1.625,00$ \\
\hline MÉDIA DE FAT VENDA & R\$ 1.250,00 & $\mathrm{R} \$ 1.875,00$ & R\$ 2.500,00 \\
\hline
\end{tabular}




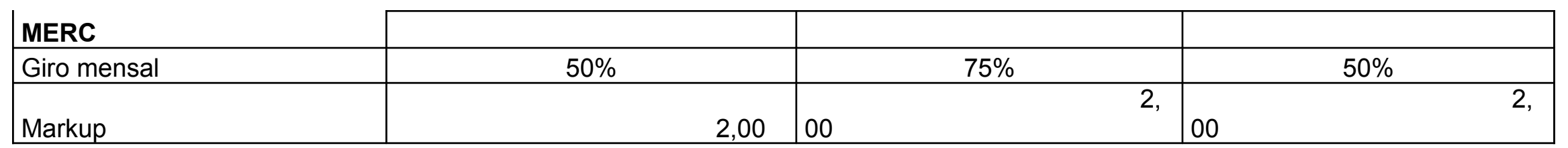

Cada Frigobar terá os seguintes itens: 02 garrafas de água, 02 lata de suco natural, 02 chocolates, 02 cervejas e 02 latas de castanhas.

Projeção de Faturamento Anual da Pousada

\begin{tabular}{|c|c|c|c|c|}
\hline \multicolumn{5}{|c|}{0} \\
\hline Referência & & & Nível $75 \%$ & Nível $100 \%$ \\
\hline Chalés & $\mathrm{R} \$$ & $225.360,00$ & $\begin{array}{c}\mathrm{R} \$ \\
338.040,00\end{array}$ & $\begin{array}{c}\mathrm{R} \$ \\
450.720,00\end{array}$ \\
\hline Frigobar & $\mathrm{R} \$$ & $5.250,00$ & $\begin{array}{c}\mathrm{R} \$ \\
7.875,00 \\
\end{array}$ & $\begin{array}{c}\mathrm{R} \$ \\
10.500,00\end{array}$ \\
\hline TOTAL GERAL & $\mathbf{R} \$$ & $230.610,00$ & $\begin{array}{c}\mathrm{R} \$ \\
345.915,00 \\
\end{array}$ & $\begin{array}{c}\mathrm{R} \$ \\
461.220,00 \\
\end{array}$ \\
\hline
\end{tabular}

Fonte: Modelo planilhas Manual de Planejamento do autor Manoel Isnard Ribeiro Almeida (2003) 
Tabela 7 - Avaliação da Viabilidade Financeira - Pousada Ecológica Chapada Imperial

\begin{tabular}{|c|c|c|c|c|c|}
\hline LUCRO LÍQUIDO ANUAL & $50 \%$ & $\%$ & PE & $75 \%$ & $100 \%$ \\
\hline Faturamento (Fat) & R\$ 230.610,00 & $100,0 \%$ & R\$ 265.489,51 & R\$ 345.915,00 & $\mathrm{R} \$ 461.220,00$ \\
\hline Custos Variáveis (CV) & $\mathrm{R} \$ 168.345,30$ & $73,0 \%$ & $\mathrm{R} \$ 193.807,34$ & $\mathrm{R} \$ 211.008,15$ & $\mathrm{R} \$ 292.874,70$ \\
\hline Margem de Contribuição (MC) & $62.264,70$ & $27,0 \%$ & $71.682,17$ & $\mathrm{R} \$ 134.906,85$ & $\mathrm{R} \$ 168.345,30$ \\
\hline Custos Fixos (CF) & $71.682,17$ & $31,1 \%$ & $71.682,17$ & $\mathrm{R} \$ \quad 71.682,17$ & $\mathrm{R} \$ \quad 71.682,17$ \\
\hline Lucro Líquido (LL) & $\mathrm{R} \$ \quad(9.417,47)$ & $-4,1 \%$ & $\mathbf{R} \$$ & $\mathrm{R} \$ \quad 63.224,68$ & $\mathrm{R} \$ \quad 96.663,13$ \\
\hline Ponto de Equilíbrio (PE) & $\mathrm{R} \$ 265.489,51$ & $115,1 \%$ & $\mathrm{R} \$ 265.489,51$ & R\$ $183.800,43$ & $R \$ 196.389,50$ \\
\hline LUCRATIVIDADE (\%) & $-4 \%$ & & & $18 \%$ & $21 \%$ \\
\hline RENTABILIDADE (\%) & $-3 \%$ & & & $21 \%$ & $33 \%$ \\
\hline
\end{tabular}

Fonte: Modelo planilhas Manual de Planejamento do autor Manoel Isnard Ribeiro Almeida (2003) 
Tabela 8 - CASH FLOW - Pousada Ecológica Chapada Imperial - 05 ANOS (R\$)

\begin{tabular}{|l|r|r|r|r|r|r|}
\hline & 1 & 2 & 3 & 4 & 5 & TOTAL \\
\hline FATURAMENTO & $230.610,00$ & $299.793,00$ & $404.720,55$ & $566.608,77$ & $849.913,16$ & $2.351 .645,48$ \\
\hline CUSTO VARIÁVEL (53\%) & $122.223,30$ & $158.890,29$ & $214.501,89$ & $300.302,65$ & $450.453,97$ & $1.246 .372,10$ \\
\hline CUSTO FIXO & $71.682,17$ & $80.284,03$ & $89.918,11$ & $100.708,28$ & $112.793,28$ & $455.385,86$ \\
\hline DEPRECIAÇÃO & $12.942,17$ & $12.169,46$ & $11.442,88$ & $10.759,68$ & $10.117,28$ & $57.431,47$ \\
\hline RESULTADO ANO & $49.646,70$ & $72.788,14$ & $111.743,43$ & $176.357,52$ & $296.783,18$ & $707.318,98$ \\
\hline
\end{tabular}

\begin{tabular}{|c|c|c|c|c|c|c|}
\hline \multicolumn{7}{|c|}{ Tabela 9 -PREVISÃO DE DESTINO DO FLUXO DE CAIXA - 05 ANOS (R\$) } \\
\hline ANOS & 1 & 2 & 3 & 4 & 5 & TOTAL \\
\hline Resultado do período & $49.646,70$ & $72.788,14$ & $111.743,43$ & $176.357,52$ & $296.783,18$ & $707.318,98$ \\
\hline & & & & & & - \\
\hline Retirada (20\%) & $9.929,34$ & $14.557,63$ & $22.348,69$ & $35.271,50$ & $59.356,64$ & $141.463,80$ \\
\hline Reservas para capital de giro & $39.717,36$ & $58.230,51$ & $89.394,74$ & $141.086,02$ & $237.426,55$ & $565.855,18$ \\
\hline & & & Cap & le Giro Inic & Ira 3 meses & 43.172,34 \\
\hline
\end{tabular}

\begin{tabular}{|l|r|r|r|r|r|r|}
\hline \multicolumn{7}{|c|}{ Tabela 10 - CÁLCULO DA DEPRECIAÇÃO } \\
\hline IMOBILIZADO INICIAL & $216.769,00$ & $203.826,83$ & $191.657,38$ & $180.214,50$ & $169.454,81$ & $216.769,00$ \\
\hline DEPRECIAÇÃO ANUAL (\%) & $6,0 \%$ & $6,0 \%$ & $6,0 \%$ & $6,0 \%$ & $6,0 \%$ & $26 \%$ \\
\hline DEPRECIAÇÃO VALOR & $12.942,17$ & $12.169,46$ & $11.442,88$ & $10.759,68$ & $10.117,28$ & $57.431,47$ \\
\hline IMOBILIZADO FINAL & $203.826,83$ & $191.657,38$ & $180.214,50$ & $169.454,81$ & $159.337,53$ & $159.337,53$ \\
\hline
\end{tabular}

Fonte: Modelo planilhas Manual de Planejamento do autor Manoel Isnard Ribeiro Almeida (2003) 


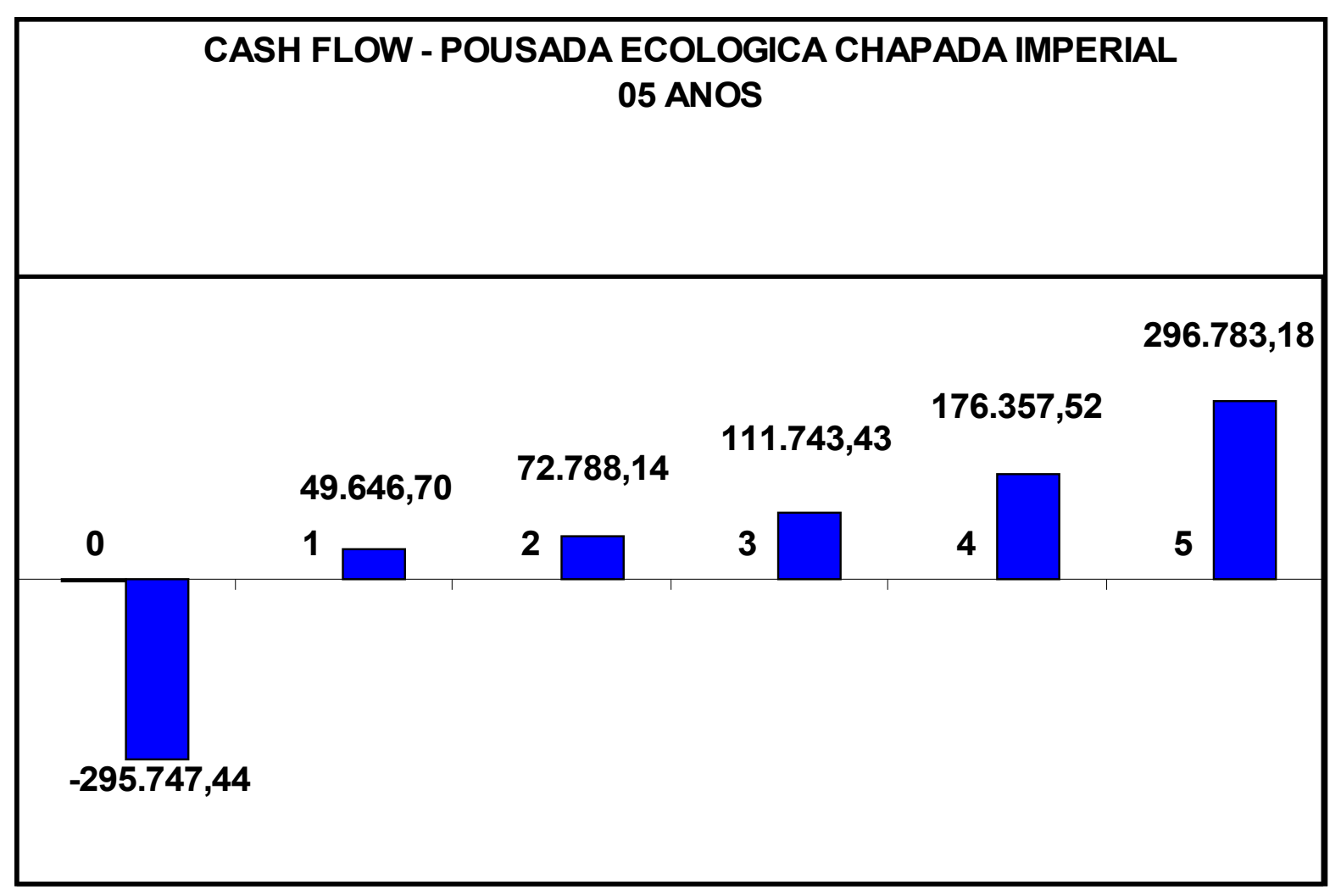

Fonte: Modelo planilhas Manual de Planejamento do autor Manoel Almeida (2003) 


\section{CRONOGRAMA DE EXECUÇÃO DO PROJETO}

\begin{tabular}{|c|c|c|c|c|c|c|c|c|c|c|c|c|c|c|c|}
\hline \multicolumn{16}{|c|}{ CRONOG R A A } \\
\hline \multirow{2}{*}{ AÇÃO } & \multirow{2}{*}{ ATIVIDADE } & \multicolumn{12}{|c|}{ Mês } & \multirow{2}{*}{\begin{tabular}{|c|} 
Ano \\
1 \\
\end{tabular}} & \multirow{2}{*}{$\begin{array}{c}\text { Ano } \\
2\end{array}$} \\
\hline & & 1 & 2 & 3 & 4 & 5 & 6 & 7 & 8 & 9 & 10 & 11 & 12 & & \\
\hline 1 & $\begin{array}{l}\text { Contratação de Empresa } \\
\text { de Consultoria para o } \\
\text { Estudo de Impacto } \\
\text { Ambiental }\end{array}$ & I & I & I & & & & & & & & & & & \\
\hline \multirow{4}{*}{2} & $\begin{array}{l}\text { Contratação de Empresa } \\
\text { de Arquitetura e } \\
\text { Engenharia }\end{array}$ & & & & & & & & & & & & & & \\
\hline & Compra de material & & & & & & & & & & & & & & \\
\hline & Inicio da Obra & & & & & & & & & & & & & & \\
\hline & Duração da Obra & & & & & & & & & & & & & & \\
\hline \multirow{3}{*}{3} & Contratação de Decorador & & & & & & & & & & & & & & \\
\hline & Compra de Equipamentos & & & & & & & & & & & & & & \\
\hline & $\begin{array}{l}\text { Compra de móveis e } \\
\text { utensílio }\end{array}$ & & & & & & & & & & & & & & \\
\hline \multirow{4}{*}{4} & $\begin{array}{l}\text { Contração de Empresa de } \\
\text { Marketing para elaborar } \\
\text { Campanhas de Divulgação }\end{array}$ & & & & & & & & & & & & & & \\
\hline & $\begin{array}{l}\text { Trabalho de Promoção e } \\
\text { Divulgação }\end{array}$ & & & & & & & & & & & & & & \\
\hline & $\begin{array}{l}\text { Contratação para empresa } \\
\text { para dar Treinamentos aos } \\
\text { funcionários }\end{array}$ & & & & & & & & & & & & & & \\
\hline & $\begin{array}{l}\text { Contratação de } \\
\text { funcionários e treinamento } \\
\text { socio-ambiental }\end{array}$ & & & & & & & & & & & & & & \\
\hline \multirow{4}{*}{5} & Recebimentos da Obra & & & & & & & & & & & & & & \\
\hline & $\begin{array}{l}\text { Montagem de } \\
\text { Equipamentos }\end{array}$ & & & & & & & & & & & & & & \\
\hline & $\begin{array}{l}\text { Montagem de móveis e } \\
\text { Utensílio }\end{array}$ & & & & & & & & & & & & & & \\
\hline & $\begin{array}{l}\text { Limpeza das Instalações } \\
\text { para a inauguração }\end{array}$ & & & & & & & & & & & & & & \\
\hline 6 & Inauguração & & & & & & & & & & & & & & \\
\hline
\end{tabular}

Fonte: Modelo planilhas Manual de Planejamento do autor Manoel Isnard Ribeiro Almeida (2003) 


\section{METODOLOGIA}

Levando em consideração os princípios de sustentabilidade, propõe-se a implantação de uma Pousada Ecológica na Chapada Imperial que é um local baseado na idéia de desenvolvimento sustentável.

Os requisitos desenvolvidos para a implantação de um meio de hospedagem ecológica "Pousada Ecológica na Chapada Imperial", foi sobre tecnologias limpas e procedimentos capazes de promover os resultados esperados, permitindo assim um planejamento e eficiente para a concepção deste empreendimento.

Foi estudado entre outras fontes de pesquisa, sobre conceitos de planejamento estratégico, sustentabilidade, desenvolvimento sustentável e a Hotelaria para alcançar um embasamento teórico do projeto.

Depois de várias visitas ao local, entrevistas com os proprietários da fazenda e aplicação de questionário aos funcionários, visitantes e membros da comunidade local, estima-se para a "Pousada Ecológica na Chapada Imperial", que sua operacionalização terá condições favoráveis à qualidade ambiental e econômica.

Para a concepção do projeto será encomendado um estudo de Impacto Ambiental para saber qual o melhor local, dentro da Chapara Imperial, que deverá ser construído o empreendimento e as licenças obrigatórias para sua legalidade.

A Pousada Ecológica na Chapada Imperial utilizará a construção sustentável e outras técnicas para um melhor aproveitamento dos recursos naturais, a fim de reduzir o impacto ambiental de sua atividade. Será contrato uma empresa de engenharia e arquitetura que melhor trabalhe com bioconstruções.

Para minimização do custo, foram feitas pesquisa de preços acerta de materiais, mão de obra, móveis e equipamentos para garantir a sustentabilidade econômica do empreendimento.

Acerca da gestão sustentável do empreendimento, considera-se possível o aproveitamento da mão-de-obra local para a operacionalização da Pousada Ecológica na Chapada Imperial. Será contrato uma empresa de recrutamento e seleção para o treinamento dos futuros colaboradores, sempre baseados em princípios da sustentabilidade. 
Para a sustentabilidade sócio-econômico da população pretende-se formar parcerias junto à comunidade local para a promoção de melhoria da renda, produção de bens e serviços turísticos. 


\section{CONSIDERAÇÕES FINAIS}

O objetivo do projeto é a Implantação de um projeto de Pousada Ecológica na Chapada Imperial, lugar de lazer no Distrito Federal. É importante mencionar que Brasília - ainda considerada uma cidade bastante nova - diferentemente de outros Estados considerados seculares, não apresenta muitas opções de lazer. O entorno, no entanto, é abastado de riquezas naturais que, muitas vezes, são exploradas sem qualquer consciência ambiental, visando simplesmente o lucro, resultando no aviltamento e destruição do meio.

A Chapada Imperial se caracteriza como um modelo positivo da importância de atividades turísticas para o desenvolvimento do meio rural, propiciando o crescimento do número de empregos, aumento da renda, fixação do homem no campo e preservação dos ecossistemas.

As ações de promoção do turismo rural na Chapada Imperial integram a estratégia de conservação da biodiversidade, uma vez que constitui geração de renda com baixo impacto ambiental. A implementação dessas estratégias são resultado de uma intensa preparação, tanto de projetos de infra-estrutura, planejamento constante e monitoramento, quanto de sensibilização dos funcionários e visitantes.

Princípios e técnicas do ecoturismo são, ainda, utilizados na Chapada Imperial, para despertar nos visitantes a sensibilização para o Cerrado, além de desenvolvimento de pesquisas e educação do homem do Cerrado, propiciando o desenvolvimento harmonioso, consciente e equilibrado.

O desenvolvimento do ecoturismo na Chapada Imperial encontra-se ligado ao planejamento de preservação do ambiente natural onde se insere o empreendimento, sendo que a dinamização do empreendimento se fundamenta em critérios rígidos de controle ambiental, preocupado com resíduos, geração e controle de efluentes (esgoto gerado), economia de recursos naturais, segundo critérios de sustentabilidade ambiental (3R - reduzir, reutilizar e reciclar), utilizando estruturas 
planejadas de obras civis e condução sanitária e a aplicação efetiva de educação ambiental.

A implantação do ecoturismo na Fazenda Dois Irmãos se tornou uma alavanca dinâmica para a preservação integral do cerrado na propriedade, uma vez que a proteção ambiental visando à exploração comercial demonstrou uma boa viabilidade econômica, podendo manter a integridade do bioma, substituindo com vantagens o manejo tradicional da terra, existindo, portanto, uma utilização profissional do espaço, explorando o meio natural com vantagens econômicas valoráveis que suplantam o modelo tradicional.

Essa situação abre os precedentes de utilização sustentável dos recursos naturais, encampando a preservação do meio ambiente como atividade econômica competente e suscetível de sobrevivência em um mercado turístico altamente competitivo e ávido por empreendimentos eficazes e comprometidos.

O Sistema Brasileiro de Certificação de Hotéis não leva em consideração o desempenho ambiental do estabelecimento para classificá-lo. A adoção de um sistema paralelo, oficial e obrigatório, de classificação dos hotéis, que leve em conta as variáveis ambientais, promoverá a valorização deste quesito pelo empresário, assim como, permitirá ao cliente, maiores opções de escolha e incentivo à preservação ambiental.

Por fim, e de modo conclusivo, entende-se e acredita-se que esta proposta mostrou-se viável para o propósito a que se destinou, embora necessite de melhorias no que concerne à definição de critérios para a análise de significância dos impactos ambientais. 


\section{REFERÊNCIAS BIBLIOGRÁFICAS}

ABIH - Associação Brasileira da Indústria de Hotéis: Manual de Cadastramento e Qualificação de Hotéis, 1997. Disponível em: http://www.abih.com.br. Acesso em: 18 ago. 2008.

ABNT - Revista Oficial da Associação Brasileira de Normas Técnicas. Número 0. Jan/Fev. 96 e Número 2- Ano 1, Out./Nov./Dez 96.

ANDRADE, Nelson. Hotel: planejamento e projeto. 5. ed. São Paulo: editora SENAC, 2002.

ANSOFF, I. A Nova Estratégia Empresarial. São Paulo: Atlas, 1990.

ALMEIDA: Martinho Snard: Manual do Planejamento Estratégico, $2^{\circ}$ edição. São Paulo. Atlas 2003.

ARIAU. Disponível em: http://www.ariau.tur.brl. Acesso em: 15 jul. 2008.

BENI, Mário Carlos. Análise estrutural do turismo. São Paulo: SENAC, 1998.

BETHLEM, A. Estratégia Empresarial: conceitos, processos e administração estratégica. São Paulo: Atlas, 1998.

BURSZTYN, Marcel. Organizador. Para Pensar o Desenvolvimento Sustentável IBAMA/ENAP Editora Brasiliense, 1993.

BURSZTYN, Maria Augusta Almeida. Gestão Ambiental: Instrumentos e práticas - Brasília: IBAMA, 1994.

CAON, Mauro. Gestão estratégica de serviços de hotelaria. São Paulo: Atlas, 2008.

CAVALCANTE, C. Desenvolvimento e Natureza: Estudos para uma sociedade sustentável, SP Cortez, Recife PE - Fundação Joaquim Nabuco, 1995.

CHAPADA IMPERIAL. Disponível em: http://www.chapadaimperial.com.br. Acesso em: 18 jul. 2008.

CHIAVENATO. Idalberto. Recursos Humanos, 7. ed., São Paulo : 2002.

CPRATA. Disponível em: http://www.cprata.com.br. Acesso em: 18 jul. 2008.

DAHDAH, Nabil. [Entrevista]. Entrevista concedida. Brasília-DF, em 12 ago. 2008; . Idem, em 25 ago. 2008

DREW, David. Processos interativos homem-meio ambiente; São Paulo: DIFEL, 1986. 
DRUCKER, P. F. Práticas da Administração de Empresas. São Paulo: Pioneiras, 1981.

EMBRATUR. A indústria do Turismo no Brasil: Perfil e Tendências. São Paulo: Embratur, 1996.

FERREIRA, José Luiz. A Variável Ambiental como Componente na Classificação da Qualidade dos Serviços Hoteleiros. Florianópolis: Universidade Federal de Santa Catarina, 1999.

GIL, Antônio Carlos. Como Elaborar Projetos de Pesquisa. São Paulo: Atlas, 2001. . Métodos e Técnicas de Pesquisa Social. São Paulo: Atlas, 1999.

GODOY, Arilda S., Introdução à pesquisa qualitativa e suas possibilidades, in Revista de Administração de Empresas, v. 35, n. 2, Mar-Abr, 1995a , p. 57-63

HELIOTEK: Disponível em: www.heliotek.com.br. Acesso em 25 de agost. 2008.

IBAMA. Disponível em: http://www.ibama.gov.br. Acesso em: 18 jul. 2008.

IMPERIAL, Marta. [Entrevista]. Entrevista concedida. Brasília-DF, em 12 ago. 2008;

IMPERIAL, Marcelo. Idem . Idem, em 23 ago. 2008

INTERNATIONAL HOTELS ENVIRONMENT INITIATIVE (IHEI). Disponível em: http://www.ihei.org. Acesso: 18 jul. 2008.

KAPLAN, Robert S. Dos custos à performance. HSM Manament, mar/abril, 1999.

KINLAW, D. C. Empresa competitiva e ecológica: desempenho sustentado na era ambiental. São Paulo: Makron Books, 1997.

MARCONI, Marina de Andrade; LAKATOS, Eva Maria. Fundamentos de Metodologia Científica, 5a. Ed., São Paulo, Atlas, 2003.

MATHEUS, Carlos Eduardo. MORAES, América Jacintha de. CAFFAGNI, Carla Wanessa A. Educação Ambiental para o Turismo Sustentável. São Carlos: Rima, 2005.

MINTZBERG, H. LAMPEL, J. AHLSTRAND, B. Todas as Partes do Elefante. HSM Management. Jan/fev 1999, p. 100-108.

NELSON, Sherre Prince. PEREIRA, Ester Maria. Ecoturismo: Práticas para Turismo sustentável. Manaus: Valer, 2004.

OLIVEIRA, Djalma Pinho Rebouças de. Planejamento estratégico: conceitos, metodologia e práticas. 21.ed. São Paulo: Atlas, 2004. 
OLIVEIRA, Silvio Luiz de. Tratado de Metodologia Científica, 2. ed., São Paulo, Pioneira: 1999.

PEREIRA, Doralice Barros. Os conflitos de uso e desuso em unidades de conservação, a região da Serra do Cipó, Minas Gerais. In: IX Encontro Nacional da ANPUR. 2001. Rio de Janeiro, Anais do IX Encontro Nacional da ANPUR. Rio de Janeiro, IPPUR. Vol. 02 pp. 1124-1134.

PETRILLO, Tupac Borges; BORBA, Elayne Palma. Plano de Gestão Ambiental Fazenda Dois Irmãos e Chapada Imperial. Relatório Técnico, 2002.

QUEIROZ, M.I.P. de. Relatos Orais: do “indizível” ao "dizível”. Ciência Cultura, 39 (3): São Paulo, 1987

RATTNER, Henrique. Tecnologia e Desenvolvimento Sustentável, 1992.

RICCI, R. Hotel - gestão competitiva no século XXI: ferramentas práticas de gerenciamento aplicadas à hotelaria. Rio de Janeiro: Qualitymark, 2002.

RUSCHMANN, D. V. M. Turismo e Planejamento Sustentável: A Proteção do Meio Ambiente. 13. ed. São Paulo: Papirus Editora, 2006.

RURALTUR - Sindicato de Turismo Rural e Ecológico do DF. Disponível em: www.ruraltur.com.br, Acesso em 24 de jul. 2008

SEBRAE. - Aprender a empreender: Implantação e Gestão de Pequenos Meios de Hospedagem. Manual do participante. Sebrae-SP/ Sebrae/Nacional, 2003.

STONER, J. A. F. FREEMAN, R. E. Administração. Rio de Janeiro: Prentice-Hall do Brasil, 1995.

THOMPSON JR, A. A. STRICKLAND III, A. J. Planejamento Estratégico: elaboração, implementação e execução. São Paulo: Pioneira, 2000.

TRIGUEIRO, Andre. Mundo Sustentável: Rio de Janeiro: Sextante, 2003.

UICN - União Internacional para a Conservação da Natureza; PNUMA - Programa das Nações Unidas para o Meio Ambiente, WWF - Fundo Mundial Para a Natureza, publicação de vários colaboradores sob o título Cuidando do Planeta Terra - Uma Estratégia para o Futuro da Vida, tradução de Lenke P. A. Araújo e José Rubens Siqueira. São Paulo: Editora CL-A Cultural, 1991.

VALE, Maria Leônia Alves do. Modelo de Gestão Hoteleira para Meios de Hospedagem Ambiental e Ecológico. Universidade Federal de Santa Catarina. Manaus, 2003.

VALLE, Cyro Eyer do. Qualidade ambiental: como ser competitivo protegendo o meio ambiente: como se preparar para as Normas ISO 14000. São Paulo: Pioneira, 1995. 
VERGARA, Sylvia Constant. Projetos e Relatórios de Pesquisa em Administração. São Paulo: Atlas, 2002.

VIEIRA, Paulo Freire; WEBER, Jacques (org.). Gestão de recursos naturais renováveis e desenvolvimento: novos desafios para a pesquisa ambiental. São Paulo, Ed. Cortez,1997.

YIN R. K. Estudo de caso: planejamento e métodos. Tradução Daniel Grassi, 2ed., Porto Alegre: Atlas,2001. 


\section{APÊNDICE}

\section{ROTEIRO DE ENTREVISTAS}

Entrevista com Marta Imperial e Marcelo Imperial

Quem são os proprietários?

Família Imperial

Qual o tamanho?

800 alqueires

No inicio qual foi à atividade principal da fazenda?

criação extensiva de gado de leite.

E hoje qual a atividade principal?

O turismo

Quais os parceiros da Chapada?

IBAMA, Corpo de Bombeiros e algumas Intuições de Ensino.

Quanto ao impacto ambiental, quais os projetos, quais as ações?

A de minimização da degradação tanto nas trilhas como na área construída o modelo mais importante são as fossas ecológicas.

Existe documentação de APAS, licença ambiental, etc?

A Chapada Imperial está dentro de uma Área de Proteção Ambiental da Cafuringa APA.

Quanto à sustentabilidade. existem atividades ou projeto para promover a sustentabilidade social, ambiental e econômica da chapada?

O projeto Chapada Imperial é baseado da idéia de desenvolvimento sustentável. O turismo foi à solução encontrada para manter a preservação do lugar.

Os trabalhadores da fazenda são a priori da comunidade local com capacitação periódica, sobre o ofício e sobre a preservação do cerrado e da própria comunidade. 
Temos vários projetos nesse sentido. Produção artesanal de doces, licores e conservas em parceria com as mulheres da região. O projeto Bicho Livre em parceria com o IBAMA, onde são realizadas solturas de animais silvestres com o acompanhamento e monitoramento do IBAMA. O projeto de Inclusão com crianças carentes de abrigos e escolas que são recebidos na reserva a custo zero para elas para aprenderem o respeito à natureza e a vida de uma forma geral. O projeto do Museu Eco-Histórico de resgate da cultura rural local com seus modos de vida, ofícios e interação com a vida silvestre. O banheiro verde, construído para servir de modelo de aproveitamento de lixo. Telha de tetra parks reciclada, lâmpadas de garrafas pet, fossa ecológica e coletores solares com pets e tetra parks para aquecimento da água do chuveiro.

\section{Entrevista com o Engenheiro N. D.}

\section{Quanto custa hoje o metro quadrado de uma construção?}

Para calcular o valor exato temos que levar em consideração o porte a obra e o acabamento. Hoje de acordo com o SINDUSCON-DF o metro quadrado pode variar de $\mathrm{R} \$ 500,00$ a $\mathrm{R} \$ 1.200,00$. Como o modelo da Pousada Ecológica da Chapada Imperial é simples e rústica de custar em torno de $\mathrm{R} \$ 500,00$.

\section{Você já fez alguma construção sustentável?}

Vou iniciar o meu trabalho sustentável, nesse momento estou estudando um projeto de casa no Lago Sul toda sustentável. As obras devem iniciar em 02 meses. É um projeto simples e barato, no futuro muito breve espero realizar outros trabalhos sustentáveis.

\section{ROTEIRO DE QUESTIONÁRIOS}

Questionário aplicado aos funcionários da Chapada Imperial.

Nome:

Idade:

Quanto tempo trabalha da Chapada Imperial:

Função: 
Tem parentes que trabalham também na Chapada Imperial?

Sim ( ) Não ( )

Já participou de algum treinamento?

Sim ( ) Não ( )

Já trabalhou em algum hotel?

Sim ( ) Não（）

Já ouviu falar em ecoturismo?

Sim ( ) Não ( )

Gostaria de conhecer mais sobre sustentabilidade?

Sim ( ) Não ( )

Gostaria de trabalhar em uma Pousada Ecológica?

Sim ( ) Não ( )

\section{Questionário aplicado aos visitantes da Chapada Imperial.}

Nome:

Idade:

Quanto tempo você visita da Chapada Imperial:

Já trouxe amigos e familiares para visitar a Chapada Imperial?

Sim ( ) Não（）

Já participou de algum programa pedagógico oferecido pela Chapada Imperial? Sim ( ) Não ( )

Gostaria de ficar hospedado em uma pousada ecológica na Chapada Imperial?

Sim ( ) Não（）

Já ouviu falar em ecoturismo?

Sim ( ) Não（）

Gostaria de conhecer mais sobre sustentabilidade?

$\operatorname{Sim}($ ) Não ( )

Questionário aplicado a membros da comunidade local da Chapada Imperial.

Nome:

Idade:

Quanto tempo você é visinho da Fazenda Chapada Imperial? 
Têm parentes trabalhando na Chapada Imperial?

Sim ( ) Não ( )

Já participou de algum programa pedagógico oferecido pela Chapada Imperial? Sim ( ) Não ( )

Já trabalhou em algum hotel?

Sim ( ) Não ( )

Já ouviu falar em ecoturismo?

Sim ( ) Não ( )

Gostaria de conhecer mais sobre sustentabilidade?

Sim ( ) Não ( )

Gostaria de trabalhar em uma Pousada Ecológica?

Sim ( ) Não ( ) 


\author{
ANEXO \\ Informações e reservas: \\ (61) $99844437 \cdot 99652461$ \\ 99619068
}

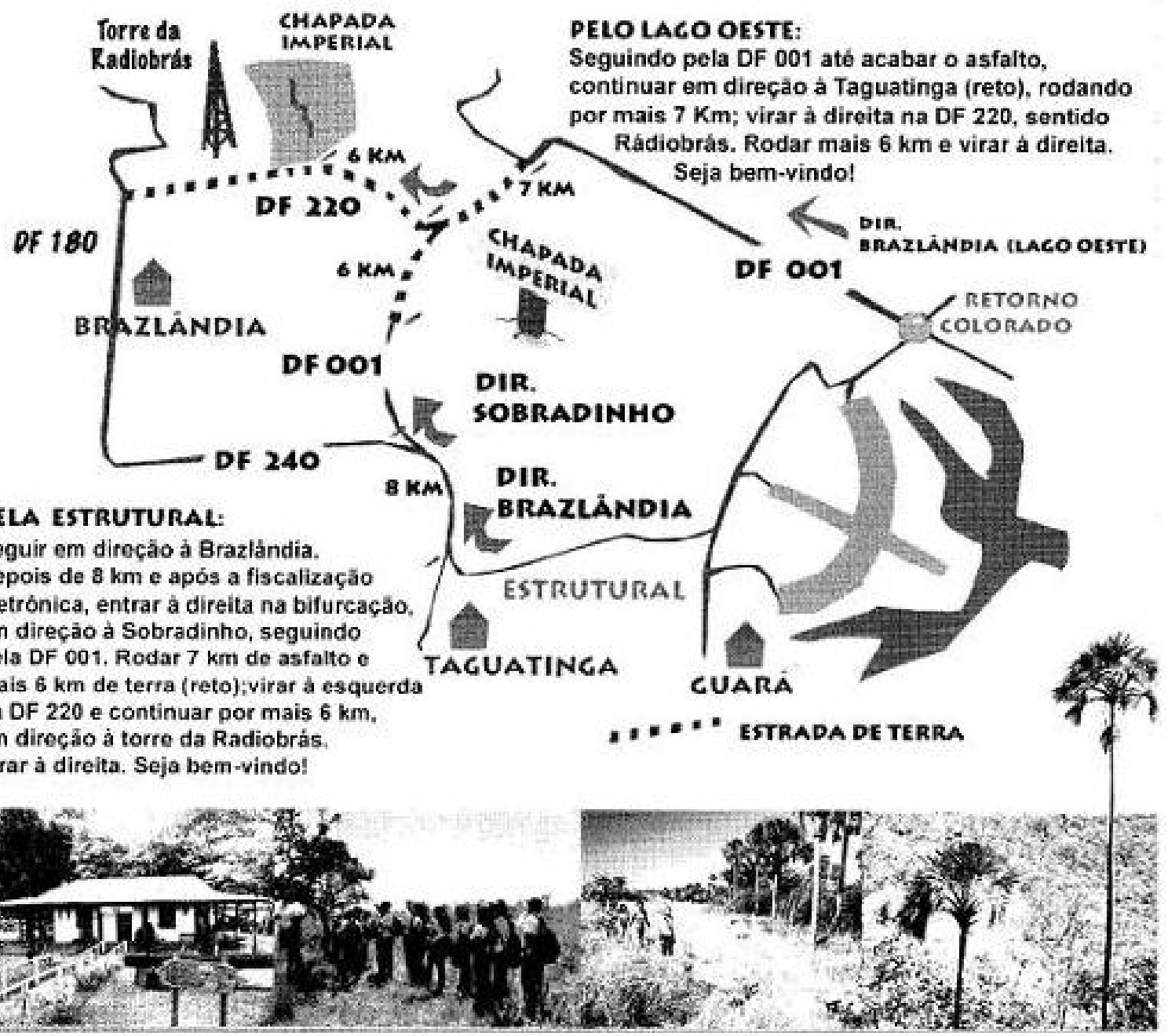

www.chapadaimperial.com.br 